\title{
Understanding How Plasmodium falciparum Binds to the Placenta and Produces Pathology Provides a Rationale for Pregnancy-Associated Malaria Vaccine Development
}

\author{
Lara C. Morley ${ }^{\#}$ and Andrew W. Taylor-Robinson*
}

Institute of Molecular and Cellular Biology, University of Leeds, United Kingdom

\begin{abstract}
By adulthood repeated exposure to Plasmodium falciparum, the causative agent of the most severe form of malaria in humans, can induce semi-immunity to clinical infection. During pregnancy, however, there is a striking recurrence of severe disease, a syndrome described as pregnancy-associated malaria (PAM). This is caused by $P$. falciparum-infected erythrocytes binding to receptors on the placental endothelium that are expressed uniquely during pregnancy. This subset of parasites binds by virtue of expressing a cell surface antigen that is the ligand for the corresponding endothelial receptor, thereby providing a selective pressure for its clonal expansion. The antigen also triggers a protective antibody-mediated immune response. With subsequent pregnancies and further exposure to these variant parasites, antibodies develop earlier and women may experience milder infections. Women with PAM exhibit more severe malaria infections than do non-gravid women, with 2,500-10,000 deaths each year due to haemolytic anaemia. PAM also has a detrimental effect on the foetus, increasing the risk of low birth weight, which causes 60,000200,000 infant deaths annually in sub-Saharan Africa. Current research aims to produce a vaccine to stimulate development of antibodies which would be protective against infection with wild-type parasites. This is hampered by significant diversity in variant surface antigens and available vaccine candidates may only protect women living in malaria-endemic areas. While placental-parasite interactions are not sufficiently understood, incremental progress is being made towards producing an effective vaccine. This review focuses on the molecular structures involved in binding to consider the prospects for a vaccine mimicking naturally-acquired immunity to PAM.
\end{abstract}

Keywords: Malaria, Placenta, Plasmodium falciparum, Pregnancy, Vaccine.

\section{INTRODUCTION}

Malaria is caused by protozoan parasites of the genus Plasmodium, with P. falciparum being responsible for the most dangerous infections in humans. Via a complex life cycle involving human and Anopheles mosquito hosts, the parasite is able to infect men, women and children of all ages. A state of semi-immunity to malaria can develop with increasing exposure to the parasite, such that adults in endemic areas may have mild or asymptomatic infections [1]. After the cessation of breast-feeding, which facilitates the passive transfer of protective antibodies from the mother, young children are particularly susceptible to severe malaria. During pregnancy, there is a pronounced recurrence of symptomatic infection, whereby malaria is $1.5-12 \mathrm{x}$ more prevalent in pregnant women compared to their non-gravid counterparts [2]. Over 50 million women worldwide are at risk of pregnancy-associated malaria (PAM), resulting in 2,500-10,000 maternal deaths annually $[3,4]$. The parasite also produces significant adverse effects for the offspring of women affected by malaria during pregnancy, by binding to

*Address correspondence to this author at the Institute of Molecular and Cellular Biology, Faculty of Biological Sciences, University of Leeds, Leeds LS2 9JT, UK; Tel: (44) 113-343-2893;

E-mail: a.w.taylor-robinson@leeds.ac.uk

${ }^{\#}$ Current affiliation: Department of Histopathology and Molecular Pathology, St James University Hospital, Leeds LS9 7TF, UK. placental structures. The resulting low birth weight of infants causes approximately 60,000-200,000 deaths each year in sub-Saharan Africa [5]. This equates to $11.4 \%$ of neonatal deaths, $5.7 \%$ of all infant deaths and $20 \%$ of low birth weight deliveries in malaria-endemic countries [6].

The rate of malaria infection is increasing for both pregnant and non-gravid populations [7]. The reasons for this are manifold and include rising levels of resistance of the parasite to chemotherapy and of the mosquito vector to insecticides, coupled with the burgeoning human immunodeficiency virus (HIV) epidemic [8]. As such, the development of a vaccine for PAM is regarded as a matter of urgency by the public health community. In recent years, there has been a significant advance in understanding the mechanism by which $P$. falciparum-infected erythrocytes bind to the placenta. This progress indicates that it may be possible to interfere with the interaction between parasite and placenta to design a blood stage vaccine specifically to prevent malaria in pregnancy.

A major question facing researchers in this field is whether the dynamic nature of highly variable parasite isolates can be overcome to produce a pan-reactive vaccine to protect pregnant women worldwide. This review examines the complex immune response to $P$. falciparum during pregnancy and the processes by which semi-immunity is hypothesised to develop. Current opinions on the genetic 
basis of parasite pathogenicity in PAM and the resulting adverse effects are also considered.

\section{LIFE CYCLE OF P. falciparum}

Malaria is transmitted via the bite of an infectious female Anopheles mosquito. Following the injection of sporozoites into the human, a schizont forms inside each infected hepatocyte, which is followed by asexual division to produce thousands of merozoites. The release of merozoites into the blood stream initiates the erythrocytic cycle that is associated with the pathogenesis of the disease (Fig. 1).

Merozoites bind to erythrocytes through a variety of ligands. This exerts pressure on the contractile filaments of the parasite, effectively forcing the merozoite into the erythrocyte [9]. This signals the start of the erythrocytic schizogonic cycle, which takes place over approximately 48 hours in $P$. falciparum. The merozoite within each erythrocyte forms an immature trophozoite ring [10]. It

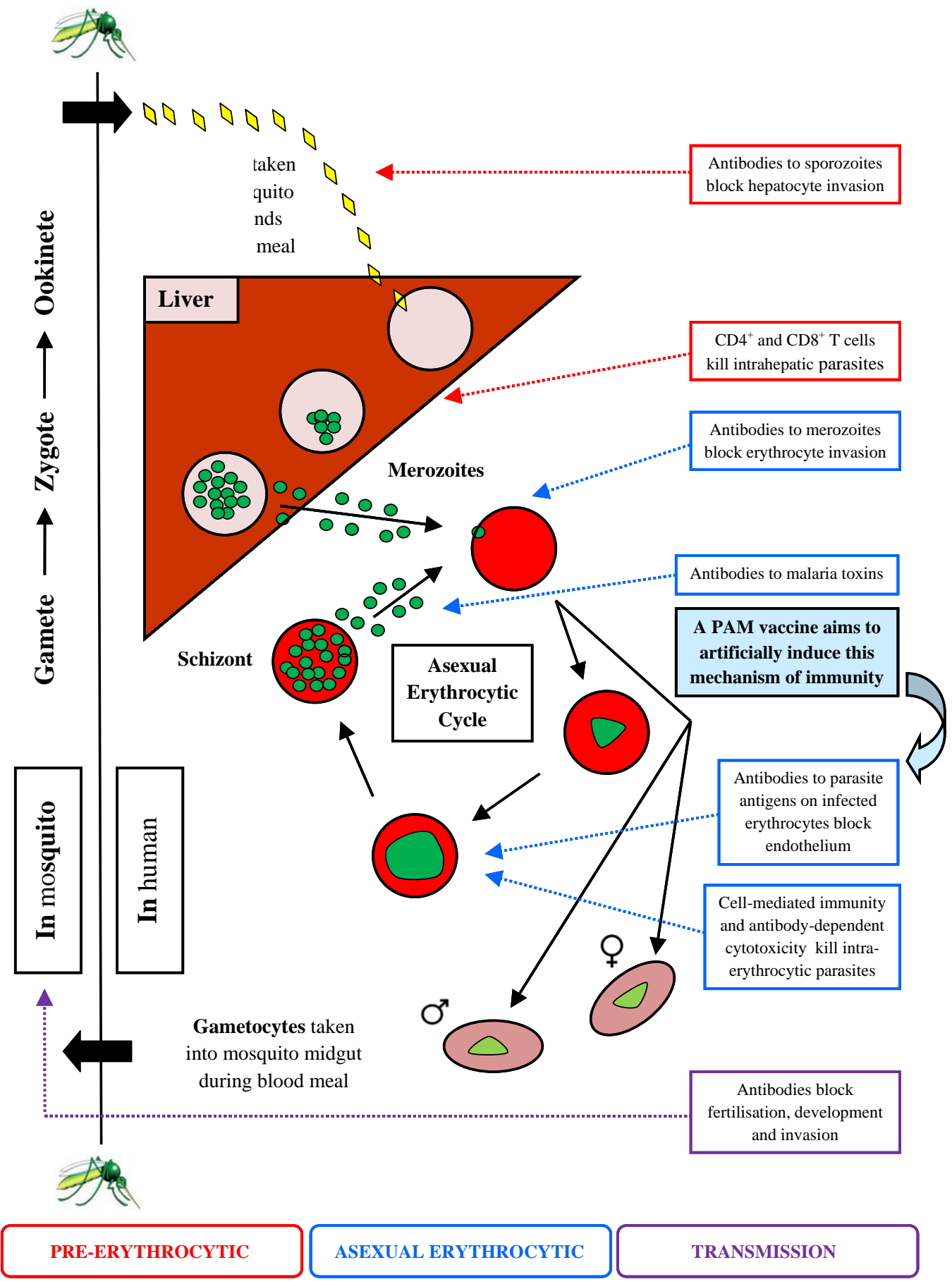

Fig. (1). Schematic life cycle of Plasmodium falciparum showing the mechanisms of immunity against different stages. An erythrocytic vaccine, such as one inducing a response to a PAM antigen, targets the asexual blood stage parasite that causes the pathology of the disease. 
receives sustenance by scavenging amino acids from the erythrocyte, since the parasite's genome does not encode protein-metabolising agents. The parasite detoxifies the iron in haemoglobin by forming haemozoin [11]. A cycle of asexual reproduction occurs, producing 8-24 merozoites per infected erythrocyte. This group of mature merozoites within the erythrocyte is known as a schizont [9]. A fraction of the merozoites mature into haploid gametocytes, which are genetically identical to the parent sporozoites and are the parasites' first sexual stage of development [9].

\section{IMMUNE RESPONSE TO PAM}

After many malaria infections, adults in endemic areas of high stable transmission develop short-lasting semiimmunity to the clinical manifestations of disease. These individuals have milder, possibly asymptomatic infections despite the presence of parasites in the blood (parasitaemia) [7]. This is due to acquired immunity, whereby an effective immune response mounts rapidly upon secondary exposure to a parasite isolate [7].

It is well documented that during pregnancy women with semi-immunity become susceptible to malaria infection once more [12]. The reasons for this are manifold but can be partly explained by alterations in the immune system which occur during the carriage of a foetus. Since the foetus is essentially a foreign body, the immune system needs to be balanced so as to not trigger an adverse immune reaction to the foetal allograft, yet maintain adequate immune protection for the mother [12]. For many years this phenomenon was explained by a maternal immunosuppressive state.

Wegmann et al., [13] first proposed that cytokines secreted by $\mathrm{T}$ helper (Th) 1 lymphocytes are harmful to pregnancy. Studies have reported that high levels of interferon (IFN)- $\gamma$, tumour necrosis factor (TNF)- $\alpha$, interleukin (IL)- 1 and IL-2 have culminated in abortion and intrauterine growth retardation when administered to pregnant animal models $[14,15]$. IFN- $\gamma$ may prevent adequate release of the growth-stimulating cytokine, granulocyte macrophagecolony stimulating factor (GM-CSF), through activation of inhibitory natural killer (NK) cells [13]. The cytotoxicity of activated NK cells can be demonstrated by foetal resorption correlating with NK cell levels. Correspondingly, antibodies to NK cells prevented foetal resorption [13].

Th1 cytokines will exert feedback on Th2 cytokines, such as IL-10. Therefore, Lin et al., [16] proposed that when IL-10 is absent and Th1 cytokines predominate, the maternal uterine epithelium is compromised, adversely affecting pregnancy outcome. Although Th1 responses are generally helpful during malaria infections, in the pregnant female they can be damaging. Researchers theorised that during normal pregnancy, Th1 cell responses are down-regulated in favour of up-regulating $\mathrm{Th} 2$ responses, resulting in the preferential engagement of B cells to fight potential infection [12]. Indeed, during normal pregnancy $\mathrm{T}$ cell-mediated autoimmune diseases undergo remission and $\mathrm{B}$ cell-mediated diseases such as allergies may become exacerbated [17]. This suppression of cellular immune responses, which may be attributed to elevated levels of circulating hormones oestrogen and progesterone, has led to the classification of pregnancy as a state of humoral immune response bias [18]. This model proposes concurrent down-regulation of IFN- $\gamma$,
TNF- $\alpha$ and IL-2. The up-regulation of Th2 appears well tolerated, with the placenta acting as an absorptive surface to prevent damaging antibody from reaching the foetus [13]. However, the suppression of Th1 cells may render pregnant women more susceptible to infectious diseases, including malaria.

According to Aagaard-Tillery et al., [17], it seems unlikely that human evolution would promote global immunosuppression during pregnancy. They demonstrated no change in numbers of B cells, T cells, antibody levels or complement between pregnant and non-pregnant females. In addition, gravid women are still able to mount normal responses to vaccines [17]. Indeed, Ashkar et al., [19] and Svensson et al., [20] have suggested that it is IFN- $\gamma$ which is necessary for a successful pregnancy, rather that IL-4. It has been postulated that IFN- $\gamma$ is involved in the defence against PAM and in the required remodelling of uterine arteries during pregnancy [19]. Aagaard-Tillery et al., [17] suggested that some cytokines may be beneficial to the conceptus, providing placental growth factors, limiting trophoblast invasion and mediating tissue remodelling.

The innate system also appears to undergo adaptation during pregnancy, whereby monocytes show a greater ability to produce the pro-inflammatory cytokines IL-12 and IL-1 $\beta$ in comparison to the non-gravid [21]. The cytotoxic capacity of the NK cell may be decreased during pregnancy, due to the expression of non-classical major histocompatibility complex (MHC) molecules HLA-E, -F and -G [17]. As such, when MHC recognition occurs killer-inhibitory receptors are activated, which serve to reduce the activity of the NK cell [17]. In particular, soluble HLA-G has been demonstrated to inhibit proliferative responses to allogeneic tissue, which is of great importance for generating an immune-privileged site for the foetus [22]. Further evidence to support this theory lies in the lack of classical MHC I and II antigens on the syncytiotrophoblast [17].

The alterations in the normal maternal immune system occurring during pregnancy are compounded by the presence of parasites. $P$. falciparum imposes a shift in the immune response from the Th2 cell emphasis of normal pregnancy to a dominant Th1 cell response [23]. This raises the concentration of potentially damaging IFN- $\gamma$, TNF- $\alpha$ and IL2 in the placenta. By binding to $\mathrm{NK}$ cells, infected erythrocytes can modify NK cell function, stimulating IFN- $\gamma$ production [23]. Increased levels of IL-10 have also been implicated in contributing to immunosuppression and maternal anaemia through disruption of erythroid progenitors [24]. In 1998, Fried et al., [25] published that of gravid women exposed to malaria, $38.3 \%$ and $42 \%$ had detectable IL-2 and IFN- $\gamma$, respectively. In comparison, pregnant women not exposed to malaria had no detectable levels of IL-2 or IFN- $\gamma$. The highest levels of IFN- $\gamma$ were seen in the primigravid $(p=0.01)$, the group in which the most severe PAM occurs [25].

\section{THE MATERNO-FOETAL INTERFACE}

$P$. falciparum exerts its damaging effects on the foetus by binding to placental structures which are developed by four months' gestation. Post-fertilisation, the embryonic blastocyst differentiates into an inner cell mass and the trophoblast [26]. The trophoblast divides further and invades 
the endometrium forming the syncytiotrophoblast. Fluidfilled cavities (intervillous spaces) form within the syncytiotrophoblast and become lined with chorionic villi. Upon hormonal stimulation this structure extends into the endometrium, connecting maternal and foetal circulation, thus forming the umbilical cord [26]. Through this structure, the foetus derives its oxygenated blood and nutrition, and receives a removal service for its waste products of metabolism [27].

\section{Pathogenicity of the Parasite}

$P$. falciparum causes the most severe malaria infections in humans due to its unique ability to sequester in the deep vascular beds of organs [9]. Sequestration enables the bloodborne parasite to avoid trafficking through the spleen, which may recognise infected erythrocytes as abnormal and destroy them. $P$. falciparum also prefers low oxygen tensions and is able to reside in post-capillary venules of the peripheral circulation [28]. The parasite also needs to ensure its infection can be maintained in order to survive and be transmitted, since the Anopheles mosquito is only active in the wet season. Therefore, sequestration can allow the parasite to remain in the human host throughout the dry season, which in some regions may last 9-10 months [29].

Parasites are able to sequester via proteins which are present on the surface of infected erythrocytes. These are expressed approximately 16 hours post-invasion, following the processes of gene expression, RNA transcription and protein translation [29]. Such antigens may correspond to receptors on the vascular tissue of organs including heart, lung, brain, liver, kidney, subcutaneous tissue and placenta [30].

\section{Molecules of Adhesion}

Research to identify the parasite ligands responsible for adhesion to the placenta has identified the variant surface antigen (VSA) P. falciparum erythrocyte membrane protein 1 (PfEMP-1) [31]. PfEMP-1 is a high molecular weight membrane protein $(200-450 \mathrm{kDa})$, which binds to vascular endothelium through its Duffy binding-like domains (DBL) [32]. These domains are cysteine-rich and organised into a tandem arrangement. Each domain is approximately 300 amino acids in length and contains 12-18 cysteine molecules and several other hydrophobic residues [33]. DBL domains are classified into subfamilies; $\alpha, \beta, \gamma, \delta, \varepsilon$ and $\mathrm{x}$ (Fig. 2). Each domain consists of short conserved motifs interspersed with regions of highly variable sequence. The cysteine-rich interdomain region (CIDR) is a degenerate DBL also present in the sequence of some var genes [33].

PfEMP-1 is membrane-spanning and is tethered to the internal surface of the erythrocyte by the acidic terminal sequence (VarC) [29]. A transmembrane (TM) region segregates the external PfEMP-1 from the genetically conserved cytoplasmic VarC sequence [29].

The endothelial molecule most commonly bound by PfEMP-1 is CD36, which acts as a receptor for infected erythrocytes on neural tissue [34]. Other inflammatory proteins implicated in mediating adhesion include thrombospondin, intercellular adhesion molecule 1 (ICAM1), vascular cell adhesion molecule-1 (VCAM-1), E-selectin and chondroitin sulphate A (CSA) [35].

$P$. falciparum samples obtained from non-pregnant individuals bound to CD36 while samples from infected placentas bound exclusively to CSA. Gamain et al., [36] demonstrated that differences in binding are due to structural alterations in PfEMP-1, resulting in adherence to either receptor. This dichotomous relationship is due to the highly diverse var multigene family which encodes PfEMP-1 [37]. Only one variant of PfEMP-1 is expressed on the infected erythrocyte surface at a particular time; hence the var genes are considered mutually exclusive [37]. Therefore, the majority of placental isolates bind to CSA and those in nonpregnant women adhere to CD36.

Research to identify the parasitic ligand which binds to CSA revealed the genes var1CSA and var2CSA. The PfEMP-1 of var1CSA binds to CSA through its DBL domains and a non-CD36-binding CIDR1 domain. The var2CSA PfEMP-1 binds to CSA through different DBL domains. In contrast, infected erythrocytes in non-pregnant tissues express a PfEMP-1 with a CD36-binding CIDR1, enabling adhesion to CD36 [36]. By adulthood, woman may have developed immunity to CD36-binding parasites
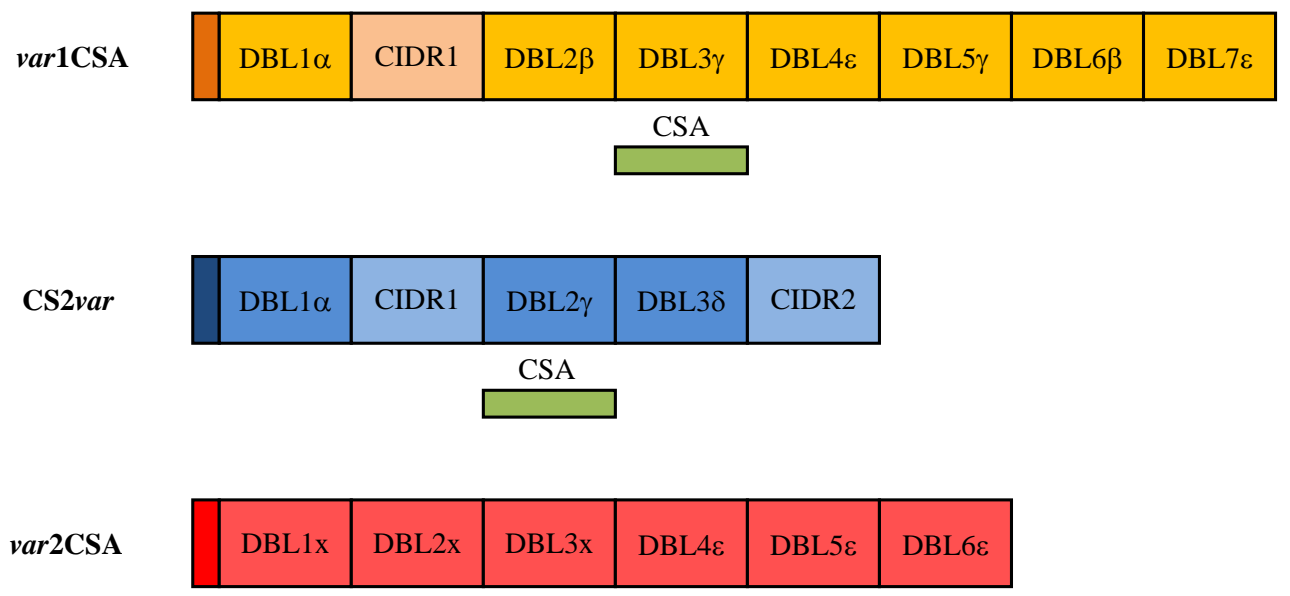

Fig. (2). Schematic representation of the extracellular domains of var genes which are implicated in binding to CSA. The CSA-binding regions demonstrated by heterologous expression and in vitro adhesion assays are highlighted. 
following multiple exposure. However, CSA-binding parasites are removed by the spleen, so limited immunity develops against this novel subset [36]. Therefore, the unique availability of CSA in pregnancy supports the clonal expansion of a different parasite variant, rendering the gravid female vulnerable to PAM [34].

Duffy and Fried [28] used an ex vivo model to observe the degree of binding to CSA, ascertaining that parasites bind within intervillous spaces along the surface of the trophoblastic villi, extravillous trophoblasts and syncytial bridges. Additionally, Fried et al., [38] demonstrated that parasite density in placental isolates correlated significantly $(p=0.0009)$ with binding to CSA.

There are approximately 50-60 var genes per $P$. falciparum haploid genome, where all 14 chromosomes contain at least one member of the var gene family [29]. The presence of var genes on each chromosome may illustrate their importance for parasitic survival. var genes share some similarities in structure including a large 5' exon and a smaller 3' exon [39]. The 5' exon is highly variable and encodes the DBL domains whereas the conserved 3' exon encodes the VarC region [29] (Fig. 2). The var genes are also positioned at a regular distance from the chromosomal telomere. This gene placement may relate to their function as promoters of recombination and genome diversity during parasite replication [29].

The var gene repertoires of different parasites were originally thought not to overlap [40]. Subsequent work identified a small group of var genes which are seemingly well conserved between parasite isolates. The initial candidate genes for binding CSA were the var genes var1CSA and varCS2 (Fig. 2). Both gene products enabled CSA binding through a common DBL $\gamma$ domain. However, varCS2 is not well conserved and is not up-regulated in CSA-binding phenotypes [41]. Antibody raised against DBL $\gamma$ was also able to react to another var gene, var2CSA
[42]. Unlike var1CSA, var2CSA contains distinct DBL domains capable of binding to CSA, namely DBL2-x, DBL3-x, DBL5- $\varepsilon$ and DBL6- $\varepsilon$, and has no CIDR domain [42].

Although var1CSA shows high intergenomic conservation and can bind to CSA, recent research has cast doubt on whether this is the dominant ligand [43] (Table 1). The principle of PAM is that a unique subset of parasites is selected for by the placenta during pregnancy. This stimulates the production of antibodies specific to the VSAs expressed during PAM, so that men and non-pregnant women do not acquire these unique antibodies. However, var1CSA does generate a pan-reactive immune response but the antibodies are neither gender- nor parity-specific [43]. When performing knock-out studies, Andrews et al., [44] found that parasites without an active var1CSA gene were still able to exhibit binding. In contrast, when investigating var2CSA, Viebig et al., [45] generated a mutant parasite isolate in which the var2CSA DBL4- $\varepsilon$ domain was replaced with an inactive cassette. Following disruption of var2CSA, the isolate was not able to bind to CSA. Salanti et al., [46] used PCR to demonstrate that, in contrast to var2CSA, the transcription of var1CSA is not up-regulated in CSA-binding parasites.

Receptor-specific panning assays have shown that var gene switching takes place but no other receptors are able to take over the binding of CSA in the absence of var2CSA [45]. Since no other protein emerges to compensate var2CSA loss, var2CSA is vital for CSA adhesion and has therefore been promoted by many groups as a prominent vaccine candidate (Table 1). Further research is required to answer key questions concerning this gene, such as identifying whether the var2CSA ligands are presented on the surface of the infected erythrocyte [33]. Although var2CSA can bind to CSA in vitro, there is no evidence as yet that it can do so in vivo.

Table 1. Evidence For and Against var1CSA and var2CSA Genes as PAM Vaccine Candidates

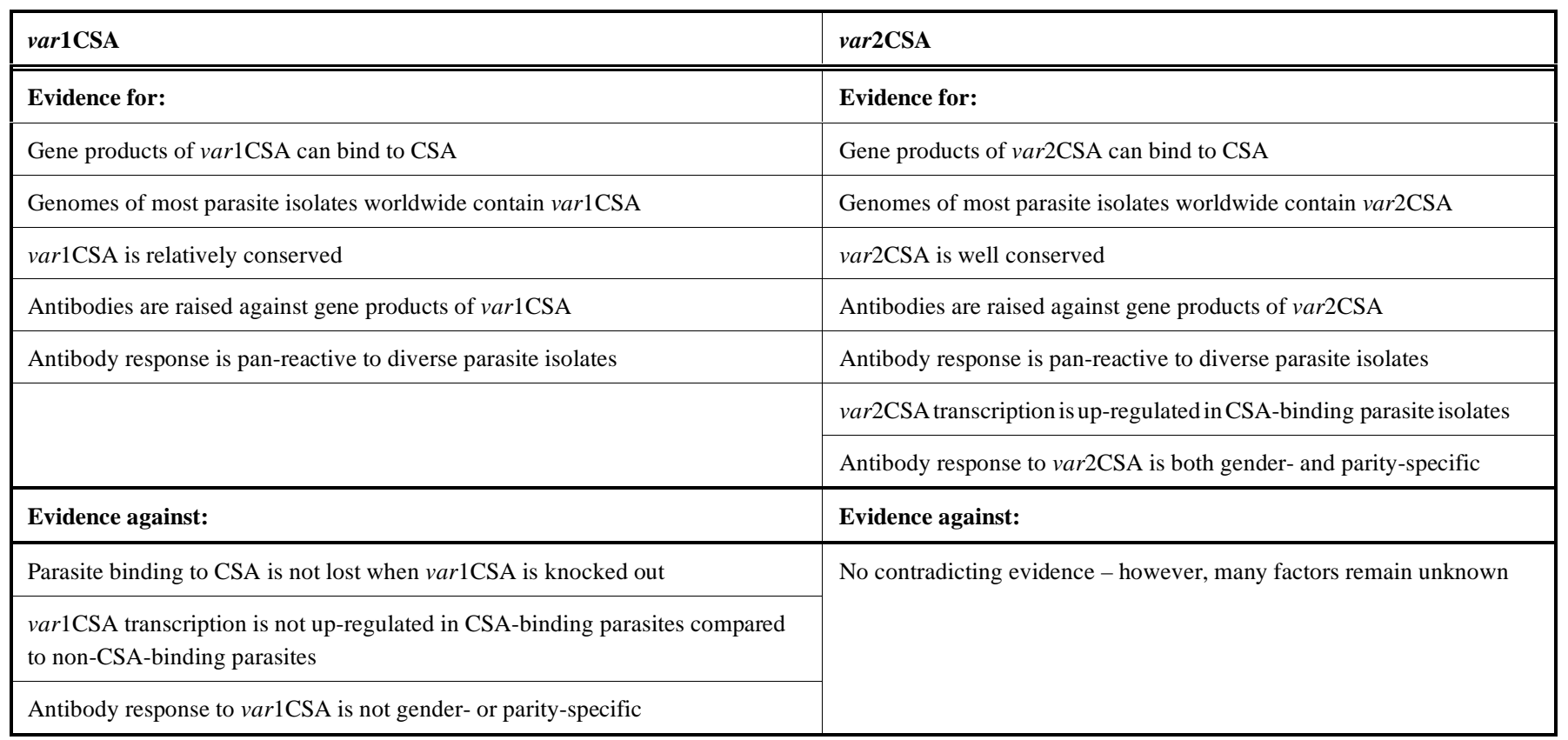




\section{The Host Receptors Interacting with the Parasitic Ligands}

CSA is a glycosaminoglycan, with repeating disaccharide units of 4-O-sulphated $\mathrm{N}$-acetylgalactosamine linked to glucuronic acid [47]. These chains need to reach $9 \mathrm{kDa}$ in size to maintain parasite binding [37]. The CSA proteoglycan chains have an unusually low level of sulphate, with less than $10 \%$ of the disaccharide units being sulphated [48]. These binding sites are located on the extracellular proteoglycan matrix of syncytiotrophoblasts of the placenta [32]. The exact domain within CSA responsible for the binding interaction with PfEMP-1 is not unequivocally known.

In 1997, Gysin et al., [49] proposed that thrombomodulin is the principal molecule responsible for CSA adhesion. However, three years later Achur et al., [27] discounted this opinion, concluding that thrombomodulin acts only as a cell surface anticoagulant. It is asserted that $80-90 \%$ of thrombomodulin lacks CSA side chains and therefore there is too limited an availability of thrombomodulin for binding. The infected erythrocyte adherence pattern differs from the expression of thrombomodulin on the surfaces of syncytiotrophoblast. Furthermore, chondroitin sulphate proteoglycans (CSPGs) mediate the adhesion and although thrombomodulin may be capable of binding, it is not the dominant receptor [27]. High quantities of CSPG can be found in the intervillous spaces, in particular those with low sulphated glycosaminoglycan chains. Further research by Muthusamy et al., [50] firmly established that these lowsulphated CSPGs are the foremost receptors for infected erythrocyte adherence.

An additional area of contention is whether there is a role for hyaluronic acid (HA) as a receptor. In contrast to CSA, HA is a non-sulphated glycosaminoglycan (GAG) formed by repeating disaccharides composed of $\mathrm{N}$-acetylglucosamine and glucuronic acid [47]. Within the normal placenta HA can be found among CSA receptors, although the GAGs of HA constitute only $2 \%$ of the total in the term placenta [27]. The positive argument for HA involvement points towards coselection experiments which indicate that many infected erythrocytes have dual specificity for binding HA and CSA, determined by variation in parasite gene sequences [47]. Chai et al., [51] observed that infected erythrocytes maintain binding to $\mathrm{HA}$ under conditions of placental $\mathrm{pH}$ and flow. The $\mathrm{pH}$ favouring binding to HA is different to that for CSA adherence, indicating that different parasite isolates may select for either receptor independently depending on placental conditions [47]. The presence of dual binding sites may present a novel mechanism of sequestration or provide enhanced adhesion for parasites binding to both HA and CSA [52]. There is no evidence as yet for antibodies developing specifically against the phenotypes of parasites binding to HA. Therefore, in the multigravid woman, chronic infection could potentially occur due to HA binding regardless of the presence of antibodies inhibiting binding to CSA.

This standpoint is challenged by Fried et al., [38], who found all adhering parasitised placental samples to bind to CSA exclusively. They reported that 3 of 60 samples bound to HA, but were not able to support binding independently of CSA. Since the parasite-binding phenotype is highly variable, some isolates may have greater affinity with the lowest sulphated CSA molecules. This may enable this minority of isolates to adhere to the low sulphated HA molecules [38]. Fried and Duffy had demonstrated previously that parasite binding could be prevented completely by treatment of the placental sample with chondroitinase in order to remove CSA, leaving little doubt that CSA is the dominant placental receptor [35]. Fried et al., [38] suggest that the high level of HA binding proposed by Beeson et al., [53] was due to contaminations of HA samples with CSA. Similarly, Fried et al., [38] theorise that the $2 \%$ quantity of HA in the placenta is an overestimate due to contamination with HA from the umbilical cord. This view is affirmed by Muthusamy et al., [54], who reported that during the second and third trimesters, when parasite binding takes place, there is no HA expressed in the intervillous space or on the syncytiotrophoblast.

Other reasons for disparate results in PAM studies include use of different parasite isolates, samples from diverse geographical areas, varying sample sizes and separate binding assays. The evidence presented here demonstrates that CSPGs of CSA are the dominant receptors and therefore that an effective vaccine would most likely mirror naturally acquired antibodies which inhibit adhesion of PfEMP-1 to these receptors.

\section{The Clinical Consequences of PAM in Relation to Protective Antibodies}

When reviewing epidemiological trends in PAM acquisition, there is clear variation dependent upon parity and transmission levels [55]. The observation that as parity increases the clinical consequences for the infected mother decline was first noted as long ago as the 1950s [56]. During pregnancy the expansion of antigenically distinct CSAbinding parasites renders existing antibodies ineffective [57].

Primigravid women are the most susceptible to severe PAM since they have no prior exposure to the CSA-binding subset. Multiparous women with antibodies are capable of exhibiting protective responses and undergoing 'natural recovery' during pregnancy [58]. Correspondingly, Fried et al., [57] studied the ability of sera to inhibit parasites binding to CSA and found that sera from primigravid women showed poor inhibition. Sera from primigravid individuals also had statistically higher parasitaemias; $p<0.0001$. By contrast, the secundigravid and multigravid samples showed binding inhibition of significant proportions; $p<0.0001$ [57].

Fried et al., [57] hypothesised that primigravid women lack anti-adhesion antibodies to CSA binding and it is this deficiency of antibodies that renders them vulnerable to PAM. These findings are controversial since O'Neil-Dunne et al., [48] studied 198 gravid women and found 92\% of primigravid women to have adhesion-blocking antibodies at term. However, the significant feature of this report is the timing of antibody development; antibodies first develop in the primigravid at around 20 weeks of pregnancy. This is consistent with the peak prevalence of parasitaemia in peripheral blood occurring between 16-19 weeks [48]. In multigravid women with previous exposure to CSA-binding parasites, immunological memory facilitates the earlier development of VSAPAM antibodies. The 'accelerated 
kinetics' result in the presence of PAM-protective antibodies at 12 weeks into pregnancy in the multigravid [34].

In contrast, these antibodies may not be apparent until 20 weeks in the primigravid, rendering these women more susceptible to the accumulation of parasites in the placenta. In the multigravid the development of antibody as a secondary response is protective, enabling the presence of parasites in the placenta to be followed closely by rapid recovery and clearance. The commonality between these findings is that with increasing pregnancies, the levels of antibodies present increase [48]. However, O'Neil-Dunne et al., [48] suggest that at term, malaria-exposed pregnant women have similar levels of anti-adhesion antibodies, regardless of their different gravidities.

These results for women in endemic areas contrast with those from regions of low or unstable transmission. In these situations there is less exposure to malaria and so few women develop protective antibodies to PAM, even with successive pregnancies. Therefore, in these areas women of all parities are at risk of contracting PAM and infections are more severe [55].

Elliott et al., [59] investigated using flow cytometry the specific nature of antibodies induced by CSA-binding VSAs. Significantly high levels of immunoglobulin (Ig) G1 and IgG3 were associated with primigravid women; $p=0.0002$ and $p=0.0004$, respectively [59]. These antibodies were raised in multigravid women but levels were on a par with the primigravid cohort. This emphasises that for protection against PAM the accelerated development of antibodies in the multigravid is more important than the quantity of antibody present. Using the Median Fluorescence Intensity (MFI) data analysis tool, levels of IgG1 and IgG3 are displayed at much greater intensity than are $\operatorname{IgG} 2$ or $\operatorname{IgG} 4$. Levels of IgG1 and IgG3 show close correlation (although there are lower levels of IgG3 compared to IgG1), suggesting that the antibodies are normally induced together [59]. The similarity in antibody profile between the primigravid and multigravid implies that the response to VSAs is the same between these two groups. It is thought that these antibodies recognise unique CSA-binding VSAs on the infected erythrocyte, preventing their adhesion to CSA. Flow cytometry demonstrated that as levels of $\operatorname{IgG} 1$ and IgG3 increase, the level of adhesion decreases, providing further evidence that these are the dominant immunoglobulins for protection [59].

The antibody $\operatorname{IgM}$ has also been found to adhere to PfEMP-1-CSA bound complexes. The function of this binding is unknown; however, Rowe et al., [60] hypothesised that binding of $\operatorname{IgM}$ is of benefit to the parasite, whereby non-specific $\operatorname{IgM}$ may outcompete specific $\operatorname{IgG} 1$ and $\operatorname{IgG} 3$ for binding sites on the CSA and infected erythrocyte-bound complexes, thereby inhibiting the action of $\mathrm{IgG} 1$ and $\mathrm{IgG} 3$. Indeed, PfEMP-1 can bind to CSA and IgM on adjacent sites [61]. The importance of IgM binding to the parasite is emphasised by the co-selection of the parasitic phenotypes encoding both mechanisms of binding [62]. This warrants further research to determine whether $\operatorname{IgM}$ binding is essential to the parasite.

When activated, $\operatorname{IgG} 1$ and $\operatorname{IgG} 3$ can bind to phagocytic cells, initiating phagocytosis of the foreign antigen. The phagocytes are triggered to produce cytokines, generate cytotoxicity and produce toxic oxygen and nitrogen radicals [63]. Thus, cytophilic antibodies may have an important role in opsonising infected erythrocytes, which enhances the efficiency of phagocytosis and clearance of the antigens (Smith, J.D., pers. comm.) Therefore, questions remain over whether it is the opsonising or adhesion-blocking function of these antibodies that is crucial for protection against PAM [34]. Rational vaccine design should thus consider candidates to block adhesion to CSA and cytophilic antibody candidates capable of opsonic phagocytosis [34].

\section{Adverse Effects of PAM for the Gravid Female}

The symptomatic presentation of PAM in the mother is similar to that in a non-pregnant woman, although the risk of complications and the mortality rate is greater for the gravid female. Fever is a well known symptom of malaria and with falciparum malaria febrile paroxysms occur every 48 hours [64]. These episodes present with a shock-like reaction, consisting of successive periods of extreme cold, hot and sweating [9,64]. After cessation of these phases, which last for several hours, the patient may recover slightly before the onset of the next paroxysm [64]. If infected erythrocytes adhere to the vascular endothelium of the brain, lifethreatening cerebral malaria may occur, potentially involving convulsions and persisting coma. The mortality rate for cerebral malaria is $20 \%$ in non-gravid adults, rising to $50 \%$ if pregnant [65]. Those who survive cerebral malaria are commonly left with persisting neurological sequelae, including paralysis, blindness and epilepsy [64].

Hypoglycaemia, defined as blood glucose of $<2.2$ $\mathrm{mmol} / \mathrm{l}$, is a particular problem in pregnant patients due to the demand for glucose exerted by the foetus [66]. This alters maternal carbohydrate metabolism, facilitating higher levels of glucose in the blood and reduced carbohydrate storage in maternal tissues [67]. The parasite also exerts a demand for glucose and stimulates pancreatic $\beta$ cells, resulting in hyperinsulinaemia and hypoglycaemia.

Women treated with quinine for PAM need monitoring for hypoglycaemia as the drug may induce hyperinsulinaemia, which results in reduced hepatic gluconeogenesis and increased uptake of glucose by peripheral cells [9]. Hypoglycaemia can present with non-specific symptoms similar to those of cerebral malaria, sepsis and pulmonary oedema. Untreated hypoglycaemia is associated with high mortality and may produce foetal distress [9].

Other severe manifestations of malaria include splenomegaly, dehydration, renal failure, coagulopathy, jaundice, septic or hypovolaemic shock and lactic acidosis $[64,66]$. Pulmonary oedema occurs most frequently in pregnant women and those recently delivered and has a mortality rate of $70 \%$ [9]. This is due to pulmonary capillary leakiness, resulting from fluid overload or adult respiratory distress syndrome.

Multigravid women with semi-immunity may have mild or asymptomatic malaria infections. However, they are still susceptible to the effects of circulating parasites, namely severe haemolytic anaemia. Severe anaemia $(<7 \mathrm{~g} / \mathrm{dl})$ can present rapidly in those without immunity but tends to be chronic in those with immunity. In a study of 910 gravid 
women, Shulman et al., [68] reported $14 \%$ to have severe anaemia. Interestingly, they found no significant difference in prevalence of anaemia between primigravid and multigravid groups. Therefore, women of all parities with placental malaria are at risk of developing anaemia, which may be acute or chronic.

During normal pregnancies, there is a $50 \%$ increase in plasma volume in order to provide a blood supply to the developing foetus [69]. This 'physiological anaemia' that is characteristic of healthy pregnancy can be compounded by malaria infection. The anaemia in malaria is haemolytic due to parasitic invasion of erythrocytes and immune-mediated destruction of infected erythrocytes [30]. In addition, $P$. falciparum has been found to suppress erythropoiesis by the production of TNF- $\alpha$ [64]. Pregnant women with severe anaemia can develop movement-limiting dyspnoea, palpitations and dizziness [9]. During labour, constriction of the uteroplacental circulation diverts blood back into the general circulation and causes an overall rise in systemic vascular resistance [9]. This puts women with severe anaemia at an increased risk of developing pulmonary oedema and heart failure immediately post-delivery. The blood loss occurring during labour may have profound consequences for the haemodynamics of the patient if blood supply is already compromised [9].

Given the adverse effects of PAM for women across all parities, coupled with the devastating impact upon their offspring, a maternal vaccination programme should therefore be inclusive of all pregnant women (Table 2).

\section{Clinical Consequences for the Foetus and Developing Child}

It is difficult to calculate the true toll of PAM upon foetal and newborn morbidity and mortality since many deaths occur at home, in rural areas and may mimic the clinical features of other infectious diseases [70]. A very common manifestation of PAM is low birth weight (LBW) newborns $(<2500 \mathrm{~g})$. This alone is thought to be responsible for 62,000-200,000 infant deaths annually in sub-Saharan Africa [71], which equates to $13 \%$ of all infant deaths in malariaendemic African countries [5]. The mean reduction in birth weight following PAM is a significant 55-310g [5]. LBW can result from premature labour and/or intrauterine growth retardation, occurring at higher frequencies when mothers are infected. Prior maternal exposure to malaria also determines foetal outcome, where a greater percentage of LBWs occurs in babies born to primigravid mothers. As such, stillbirths, abortions and neonatal deaths may occur more frequently when maternal immunity is lowest [58].

Various mechanisms have been proposed to explain the pathogenesis of LBW. One proposal is that sequestered parasites and associated cells produce a mechanical blockage that compromises nutrient transfer across the placenta [72]. Evidence for this can be seen microscopically, whereby all PAM samples possess parasites in the intervillous spaces [72].

Inflammatory mononuclear cells can be identified in the intervillous spaces, where they secrete macrophage inflammatory protein- $1 \alpha$ and $-1 \beta$, IFN-inducible protein-10 and monocyte chemoattractant protein-1. These chemokines attract macrophages which phagocytose infected erythrocytes [73]. Areas of necrotic syncytiotrophoblast are associated with the loss of microvilli and trophoblastic membrane thickening due to deposition of collagen fibres [55]. This scarring may limit gas and nutrient exchange across the placenta, causing foetal hypoxia [74]. According to Duffy [74], levels of soluble factors and nutrients have not provided evidence to prove this theory. However, parasitaemia and bilateral notching of the uterine arteries commonly occur in conjunction, supporting the theory that utero-placental circulation is altered by malaria infections potentially leading to foetal hypoxia [75].

Inflammation also contributes to placental pathology, where PAM is associated with up-regulated inflammatory cytokines such as TNF- $\alpha$ and IFN- $\gamma$. Duffy [74] found that placental levels of TNF- $\alpha$ and IFN- $\gamma$ have been associated with poor outcomes due to malaria, including LBW and severe maternal anaemia. Similarly, Rogerson et al., [76] found levels of TNF- $\alpha$ to be raised in Kenyan primigravidae with severe anaemia. The presence of inflammatory monocytes in intervillous spaces also correlates positively with parasite density and negatively with birth weight, and is inversely associated with maternal haemoglobin in multivariate analysis [76].

PAM is not commonly transmitted across the placenta, therefore true congenital malaria is rare with an estimated prevalence of only $7 \%$ in newborns in endemic areas $[64,77]$. This was demonstrated by Duffy and Fried [28],

Table 2. Consequences of Malaria in Pregnancy in Areas of Different Transmission

\begin{tabular}{|l|l|l|}
\hline Consequence & Low Transmission Areas & Moderate to High Transmission Areas \\
\hline \hline Those at risk & All parities & Mainly primigravidae \\
\hline High fever & Yes & Often asymptomatic \\
\hline Cerebral malaria & Yes & Rare \\
\hline Pulmonary oedema & Yes & Rare \\
\hline Hypoglycaemia & Yes & Rare \\
\hline Severe anaemia & Yes & Yes; may develop slowly \\
\hline Maternal death & Yes & Yes; secondary to severe anaemia \\
\hline
\end{tabular}


whereby infected erythrocytes were unable to bind along the umbilical cord. During delivery, however, blood vessels may rupture, leading to the mixing of maternal and foetal blood and transmission of parasites [72].

Due to the transfer of protective antibodies across the placenta, infants born to immune mothers are less vulnerable to contracting malaria themselves during their early months. It is possible that the transfer of parasitic antigens provides an early stimulation of the foetal immune system while in utero [78]. However, the rates of infant infection born to any woman with PAM are greater than those to mothers unaffected by PAM, regardless of gravidity. Therefore, the clinical sequelae of PAM affect the mother, foetus and developing child.

\section{EVIDENCE SUPPORTING THE PRESENCE OF ANTIBODIES AS PROTECTIVE AGAINST CLINICAL MALARIA}

Two leading research groups analysed the relationship between anti-VSAPAM antibodies and clinical outcome to determine whether the binding inhibition afforded by these antibodies impacts upon mother and baby. Both groups report that gravid women with antibodies have babies with significantly higher birth weights than those without $(p=0.10)$ [79, 80]. In real terms, Duffy and Fried [79] reported that women with effective antibodies had babies that were $398 \mathrm{~g}$ heavier on average. Similarly, Staalsoe et al., [80] reported an average difference in birth weight of $260 \mathrm{~g}$ between women with high and low levels of antibodies.

Women of higher parities with greater levels of antiVSAPAM antibodies are also more likely to carry their babies to term. The beneficial effect of antibodies on gestational age isolated from parity is also evident, where the average number of weeks gestation before birth is higher in women with antibodies [79].

Duffy and Fried [79] have reported that there is no association between anti-VSAPAM antibodies and rates of maternal anaemia. It would be logical that increasing antibodies would correlate with rising haemoglobin as a protective effect. Interestingly, Staalsoe et al., [80] report a significant difference in haemoglobin levels in women with or without antibodies, $92 \mathrm{~g} / \mathrm{l}$ vs. $76 \mathrm{~g} / \mathrm{l}$, respectively. This concurs with a 2001 meta-analysis which reported a 13-19 g/l difference dependent upon maternal antibody levels [4]. This disparity in results may be due to confounding factors, whereby anaemia has many causes including micronutrient deficiency and neither study accounted for this. The rates of malnutrition prevalent in each study range are unknown, so if there were high levels of anaemia due to dietary deficiency in the area where Duffy and Fried worked, this would reduce the impact of anti-VSAPAM antibodies on haemoglobin levels. Also of relevance is the difference in study design, whereby Duffy and Fried [79] only compared primigravid with secundigravid women, whereas Staalsoe et al., [80] included women of all gravidities in their analysis.

Care must be taken when analysing data reviewing the effects of antibodies on maternal and birth outcome, since results may vary depending on endemicity, due to differing parasite exposures. In this case, Duffy and Fried [79] worked in an area of higher transmission than did Staalsoe et al.,
[80], which makes it more difficult to make direct comparisons between the results. As a further example, Tuikue Ndam et al., [81] found no association between the level of var2CSA antibodies and clinical outcome. This may be due to women presenting predominantly with acute placental infections at birth, whereas the early development of antibodies may be more important in ameliorating the clinical manifestations of PAM during chronic infections [81].

These findings draw together the above discussion that the clinical effects of PAM are lessened by increasing parity, where the protective effect is mediated be developing antibodies. This strengthens the prospects for vaccine design based on a model of anti-adhesion antibodies, since it would likely have a clinically protective effect [80].

\section{CO-MORBIDITY AND IMPLICATIONS FOR VACCINATION}

In determining the global impact of malaria in pregnancy, it is relevant to review the interaction between PAM and other disease processes. The majority of pregnant women with malaria live in developing countries where nutritional deficiencies, haemoglobinopathies and hookworm infections, for instance, are common occurrences. Such conditions are mutually aggravating, resulting in more severe clinical outcomes. Since the emergence of HIV, there have been increasing concerns about pregnant women infected with both malaria and HIV [82]. In sub-Saharan Africa the prevalence of HIV in pregnant women can be as high as $40 \%$ [83], with up to $65 \%$ of pregnant women affected by malaria [3].

There is a well documented association between HIV infection and increased susceptibility to malaria [84]. During HIV infection the adaptive immune response becomes compromised, weakening the defence against malaria infection [82]. In 2004, Mount et al., [85] demonstrated that anti-VSAPAM antibodies were reduced in co-infected women, thereby impairing host defence against placental binding of the parasite to CSA in the placenta. Unsurprisingly, HIV-infected women with the lowest CD4 ${ }^{+}$ $\mathrm{T}$ cell counts had the most reduced levels of anti-VSAPAM antibodies [85]. HIV also induces the down-regulation of some cytokines of the cellular immune response, such as IL12 and IFN- $\gamma$ and causes destruction of memory $\mathrm{T}$ cells, leading to reduced ability to clear the parasite from the placenta [82]. HIV infection appears to impair the normal acquisition of immunity to PAM. Therefore, the effects of this dual association are most marked in the multigravidae, unlike cases in which malaria infection occurs in isolation [82].

Malaria may impact upon HIV infection in pregnant women, whereby malaria infections are thought to stimulate increased expression of $\mathrm{CC}$ chemokine receptor 5 on dendritic cells in intervillous tissues. This receptor mediates the attachment of HIV virions to macrophages, facilitating infection [86]. Immune factors active in malaria infection, such as TNF- $\alpha$, may act to trigger HIV replication [82].

The relationship between co-infection and risk of vertical HIV transmission is complex and studies have produced contradictory results. Ayisi et al., [87] demonstrated that 
among co-infected women high density placental malaria (> 10,000 parasites/ $\mu 1$ ) was associated with increased risk of mother-to-child HIV transmission, in comparison to low density placental malaria $(<10,000$ parasites $/ \mu 1)$. Ned et al., [82] suggest that in immunocompetent women, as measured by their $\mathrm{CD}^{+} \mathrm{T}$ cell count, the risk of vertical transmission is not unduly affected. However, when these women become immunocompromised, their reduced protective responses lead to higher parasite density and viral load.

The clinical consequences of infection with both PAM and HIV are profound for the foetus; dual infection among primigravidae has been associated with a three-fold increased risk of LBW, almost a three-fold increased risk of prematurity, and approximately a two-fold increased risk of 'small for gestational age' babies [88]. In the mother, coinfection incurs a greater risk of severe anaemia among all parities [88]. The successful administration of a vaccine to prevent PAM could have an important role in countering the increased susceptibility of HIV-infected women to malaria and in preventing the rise in viral load induced by malaria.

Placental parasitaemia can disrupt the transplacental passage of antibodies, which ordinarily serves as an early boost to the neonate's immune system. It is hypothesised that repeated malaria infections in the mother overstimulate $B$ cells, producing hypergammaglobulinaemia due to increased antibody production [89]. At the materno-foetal interface antibodies are transported actively across the placenta, involving mature and neonatal receptors for $\mathrm{IgG}, \mathrm{Fc} \gamma \mathrm{R}$ and $\mathrm{hFcRn}$, respectively, on the syncytiotrophoblast [89]. As described earlier, the infected erythrocytes can damage the ultrastructure of the placenta, which may impair the passage of these antibodies to the foetus. Alternatively, hypergammaglobulinaemia may outcompete transport receptors in the placenta. This prevents specific antibodies, such as those raised against respiratory syncytial virus, pneumococcus, herpes simplex-1 and varicella zoster virus, from crossing the placenta [89] (Table 3). This may render newborns, particularly those not breast-fed, more susceptible to infection during their first months [89]. Similarly, PAM may adversely affect protective responses to maternal immunisation by impairing the transport of antibodies across the placenta. Several studies have demonstrated reduced levels of antibodies in newborns despite adequate maternal vaccination, such as reduced levels of tetanus, measles and pneumococcal antibodies [74].

In the $1960 \mathrm{~s}$ it was noted that children taking antimalarial chemoprophylaxis showed a greater response to tetanus vaccination $[74,90]$. As such, implementation of a successful vaccine would greatly advance defence against malaria and could bolster the level of protection against other infectious diseases [74]. Malaria has a marked effect on morbidity and mortality in areas of low endemicity, which undermines vaccination programmes present in these areas [74]. Removing PAM could thereby reduce mortality and give greater opportunity for other vaccinations to be of use (Table 3).

\section{IMPLEMENTING A PAM VACCINE IN SUB- SAHARAN AFRICA}

The increasing rate of malaria infections is due to many factors, including the burgeoning HIV epidemic described above [7]. A contributing factor is the sharp rise in mobility since the 1970 s due to increasing availability of transport, unemployment, conflict and environmental disasters [8]. This may relocate susceptible women to areas of high transmission. The number of refugees and displaced persons worldwide has grown dramatically over the past decades, leaving many people with poor access to anti-malarial chemotherapy and preventative strategies such as bed nets [91]. Impacts of increased urbanisation such as deforestation and irrigation systems serve to expand the habitat of the Anopheles mosquito, facilitating further transmission [8].

PAM also exerts a significant economic burden on households affected by the disease [90]. Although economic data are scarce, it is clear that direct costs will be incurred during both the medical treatment and aftercare of an episode of clinical malaria. Indirect costs may result from morbidity causing a loss of work-related productivity and hence reduced earning capacity [92].

PAM may be prevented through the use of insecticidetreated bed nets. Although bed nets are relatively inexpensive, sustained donor commitment is needed to ensure adequate availability and continued provision of nets to vulnerable women [92]. Recent data suggest that a median of only $2.9 \%$ of pregnant women in sub-Saharan Africa use a

Table 3. Effect of PAM on Production of Pathogen-Specific Antibodies

\begin{tabular}{|l|c|c|}
\hline \multirow{2}{*}{ Antibody Specificity } & \multicolumn{2}{c|}{ Antibody Transfer Ratio } \\
\cline { 2 - 3 } & Placental Malaria & No Placental Malaria \\
\hline \hline Herpes simplex virus type 1 (HSV-1) & $0.86 \pm 0.17$ & $1.40 \pm 0.15$ \\
\hline Respiratory syncytial virus (RSV) & $0.62 \pm 0.13$ & $1.18 \pm 0.17$ \\
\hline Varicella-zosta virus (VZV) & $0.83 \pm 0.16$ & $1.36 \pm 0.16$ \\
\hline Diphtheria toxoid (DT) & $1.31 \pm 0.14$ & $1.43 \pm 0.22$ \\
\hline Streptococcus pneumoniae & $0.64 \pm 0.23$ & $0.75 \pm 0.12$ \\
\hline Haemophilus influenza type b (Hib) & $0.70 \pm 0.22$ & $0.72 \pm 0.26$ \\
\hline
\end{tabular}

Placental transfer of antibodies for HSV-1, RSV and VZV is significantly lower in PAM-positive mother/baby pairs than in PM-negative pairs (shown in bold). PAM does not have a significant impact on the transfer of antibodies to DT, S. pneumoniae or Hib [89]. 
treated net, with $17.4 \%$ of women using a net of any kind [92].

Malaria infections can be treated successfully with a combination of chloroquine and sulfadoxine-pyrimethamine, which have long half-lives, producing a prophylactic effect [93]. However, widespread parasite resistance to these drugs has rendered chloroquine ineffective in many areas and is impacting on the use of sulfadoxine-pyrimethamine. Newer therapeutics, such as artemisinin-based regimes, are currently more expensive which limits their use [92].

Given the impact of PAM on maternal and child health, coupled with the inadequacy of preventative and therapeutic strategies, the requirement for a successful vaccine has never been greater. However, if a vaccine preventing PAM were developed, the global political, aid and scientific communities would face further testing challenges. A successful implementation strategy would require a multifaceted programme involving education providers, policymakers, aid agency support and funding. The nature of this proposed vaccine would determine what specific social considerations would need to be made for its successful implementation. The vaccine may need to be delivered during early pregnancy, which could pose problems in rural locations where access to maternal services may be limited. A means of accessing pregnant women would be through their visits to antenatal care facilities. This is supported by the World Health Organization, which advocates the involvement of malaria control strategies within its four-visit antenatal care recommendations [94]. If the number of women accessing antenatal care is high, this point of contact would be a suitable means of providing malaria control interventions [95]. A quantitative analysis conducted by the CIAM Institute of Public Health in The Gambia reports that where they operate, $99 \%$ of 1,684 women attended an antenatal clinic at least once during their pregnancy [96].

Alternatively, a PAM vaccine could require administration during adolescence. Smith and Deitsch [97] suggest that the vaccine should be administered in the teen years in a similar manner to the human papilloma virus vaccine. For a vaccine to be given to young girls, there are important social and cultural considerations. As such, operational research is required to address the optimal delivery of a PAM vaccine, in conjunction with other reproductive health programmes [95].

Of interest is the novel educational strategy run by the CIAM Institute in The Gambia. CIAM broadcasts a highly successful educational drama series via the radio that involves plotlines relating to malaria and its prevention.

\section{THEORETICAL AND PRACTICAL DIFFICULTIES WITH PAM VACCINE DESIGN}

\section{Antigenic Diversity}

Development of a vaccine for PAM is complicated by the high level of antigenic variation of the var gene family and the DBL domains that they encode. Hopes for vaccine development were raised when it was discovered that maternal antibodies are broadly reactive to geographically diverse placental isolates [57]. This implies that a panreactive immune response develops, which could be reproduced in a vaccine. This presents a paradox whereby this apparent conservation in parasite antigen presented to the immune system is at odds with the observed high antigenic variation of the falciparum genome [34]. Gamain et al., [34] proposed that this phenomenon has two explanations:

- Each parasite genotype encodes different parasitic antigens but they are all very similar;

- The var genes encoding the parasitic antigens are highly conserved between genotypes and/or contain several common epitopes.

Evidence to support the conserved nature of var2CSA and its maintenance within the parasite population has come from the discovery of common ancestral genes between the chimpanzee malaria $P$. reichenowi and $P$. falciparum [98]. It is estimated that these two species of plasmodia diverged between 6-10 million years ago [95]. It appears that var2CSA genes comprise a mosaic of these ancestral polymorphic segments that have recombined extensively between var2CSA alleles [99]. Segmentation analysis by Bockhorst et al., [99] revealed var2CSA to be composed of DBL domains in variable and conserved regions. Following this comparison of 106 var2CSA sequences from worldwide locations it was established that the $6 \mathrm{DBL}$ domains differ in their amino acid conservation by an average of $75 \%$.

Notwithstanding this high degree of polymorphism, there are comparisons in the structural arrangement of blocks of variable and conserved regions between sequences. Researchers used segmentation analysis to examine whether segments of comparable gene sequences are linked. This revealed significant local correlations between polymorphic sections of different sequences, whereby analysis of 263 segments found $90 \%$ of pleomorphic positions occur in correlated sequences. This illustrates that there are multiple site patterns within var2CSA polymorphisms, decreasing the divergence between different var gene sequences. Therefore, the ability of anti-VSAPAM antibodies to recognise global isolates of var2CSA-encoded PfEMP-1 may be due to the cross-reaction of overlapping polymorphisms between the diverse isolates [99].

\section{The Multigravid Develop Immunity in the Face of Diversity - can this be Mimicked?}

The ability of $P$. falciparum to sequester is not shared by $P$. knowlesi, primarily a malaria parasite of monkeys. This suggests that surface antigens may have had an earlier role, prior to the development of sequestration as a virulence factor. In 1999, Saul hypothesised that expression of antigens is a deliberate means of stimulating the host immune response in order to control its population density [100]. However, Kyes et al., [29] observed that parasite isolates without surface antigens have decreased virulence. An alternative theory is that VSAs of $P$. falciparum adversely affect the development and activation of dendritic cells, suppressing the immune response [101]. Kyes et al., [29] have discussed the importance of the parasite's gamete development in order for transmission. They proposed that parasites attach to tissues for the duration of gamete production, which may take 7 days. This presents a co- 
evolution of efficient parasitic transmissibility and virulence through the same mechanism. The further evolution of high level antigenic variation of the surface antigens promotes parasitic virulence by enabling evasion of host defences.

Even with extensive antigenic variation of PfEMP-1, the immune system of a multigravid female is capable of protecting against falciparum parasites. It has been proposed that a highly conserved region of var2CSA is present in most parasitic genotypes [34]. Exposure to this domain, as expressed on PfEMP-1, enables the maternal antibodies to respond to the majority of variant combinations [34]. This corroborates earlier descriptions of late induction of antibodies rendering primigravid individuals vulnerable to PAM. Nevertheless, the immune response in the multigravid woman is imperfect since low level placental infections may still occur. This suggests that conserved regions of the var2CSA proteins may be less immunodominant than variable domains [34].

A second model proposes that parasitic var2CSA has only partial commonality in epitopes between genotypes. In areas of high transmission, women may have several placental infections with different parasitic genotypes during a single pregnancy. This may require the immune system to develop a range of antibodies to these different antigens [34]. The semi-immunity of the multigravid female stems from the production of a repertoire of antibodies that is collectively able to recognise polymorphisms at sites of normally conserved domains on the antigen [34]. During each successive pregnancy the repertoire of VSAPAM-specific antibodies is expanded with every parasite exposure. This model is supported by Tuikue Ndam et al., [81], who found that for 4 of 6 placental isolates the presence of antivar2CSA antibodies did not correlate with anti-adhesive activity. This demonstrates a high level of functional heterogeneity of VSAs on infected erythrocytes.

This raises new questions such as:

For model 1:

- Is it possible to identify the highly conserved region which can elicit a globally reactive immune response?

- Once identified, could this region be used in the development of a vaccine?

For model 2:

- In order to develop immunity to PAM, is there a critical number of exposures required to different antigens?

- Could a blend of different sequences given as a vaccine serve to stimulate a range of protective antibodies?

\section{Would a Vaccine Encourage Mutation?}

On a cautionary note, there is concern that given the high variability of var genes a vaccine which effectively covers a variety of strains of $P$. falciparum could increase the selection pressure on the parasite. This could induce the var genes to mutate, producing new VSAs to which gravid women would have no immunity. The new subpopulation could proliferate exponentially due to decreased competition from other subtypes to which the vaccine responds. Scherf et al., postulate that this is likely to happen and therefore the aim should be to target the CSA-binding sites which need to be maintained in order to promote binding in the placenta [102]. However, in vivo the multigravid female remains clinically immune to falciparum malaria since further mutation of the parasite to evade the immune response does not occur.

Researchers thus need to be certain of the regions of var2CSA which bind to CSA and whether or not they encode antigens which can be globally recognised by antibodies. In 2004, Fried et al., [103] found that when reviewing the frequency of PfEMP-1 molecules, conserved variants such as var2CSA were detected relatively infrequently. Using mass spectroscopy four additional PfEMP-1 molecules were found in several placental isolates. These molecules are not yet defined and it is important to establish whether these or additional variants are involved in sequestration and to what degree.

Experiments with trypsin, a cleavage enzyme which can degrade proteins, also indicate that the molecules involved in binding at the placental interface have not been demonstrated unequivocally. In 2004, Sharling et al., found that VSAs bound to endothelial receptors were sensitive to trypsin. This was anticipated due to the high lysine and arginine amino acid content of PfEMP-1 [32]. Rather unexpectedly, there was trypsin resistance when PfEMP-1 was bound to CSA [47]. It was suggested that the rather neatly characterised binding of PfEMP-1 to CSA is actually more complex, with the possibility of additional receptors on the surface of the infected erythrocyte which have yet to be characterised. An alternate theory is that VSAPAM consists of at least two separate molecular entities: one that is trypsin-resistant and one that is trypsin-sensitive [104].

The advocates of additional parasitic ligands contradict the views of Salanti et al., [46] and Gamain et al., [34], who promulgate var2CSA as the prominent candidate. Nielsen et al., [104] attempted to provide a working solution to this unresolved issue by proposing that although the possibility of additional binding molecules cannot be excluded, the variation in trypsin sensitivity most likely results from polymorphisms in the var2CSA sequence. Nielsen et al., [104] tested different parasite isolates and found varying sensitivity to proteolysis. Furthermore, varying sensitivity was seen between different DBL domains within each line. It therefore seems most probable that sequence diversity has coded for differences in response to proteolysis. The presence of additional molecules binding CSA seems unlikely due to the positive relationship between active var2CSA and CSA binding, where CSA adhesion decreases in proportion to the proteolytic treatment of var2CSA. Therefore, if another molecule were involved in binding, it must be expressed simultaneously with var2CSA and share the same patterns of trypsin resistance and sex-specific antibody recognition in all isolates tested [104]. This is important because a vaccine targeting characterised antigens may not prevent binding if there are other as yet undefined molecules involved in the process, rendering the vaccine ineffective.

\section{Could a Vaccine be Too Effective?}

If sterile immunity were induced in the primigravid using a 'perfect' vaccine, they would not naturally acquire antibodies to PAM over successive pregnancies [105]. This 
could render these women vulnerable because if a mutant parasite strain emerged later that was not covered by the vaccine, they would have no natural immunity and would likely develop a severe infection. Thus, there is a paradox whereby the multigravid produce antibodies yet still have infected placentas at term [97]. Staalsoe et al., [80] have presented a solution to this conundrum by emphasising the role of antibodies as controlling infection in the placenta as opposed to complete eradication. Therefore, ideally a vaccine should induce a semi-immune status, whereby antibodies are generated whilst mirroring the natural state where low-grade infection continues.

\section{PREGNANCY-ASSOCIATED MALARIA VACCINE STRATEGIES}

\section{Direct Targeting of CSA}

Evaluation of host receptors on the placenta has concluded that the CSPGs on CSA are the dominant receptors. Chondroitinase can be used in vitro to remove CSA but could this or a similar enzyme act in vivo to remove or prevent the development of placental CSA? Histological staining revealed that the concentration of CSA is consistently higher in foetal tissues than in placental tissues, indicating that these molecules are of foetal origin [54]. It can be hypothesised that the CSPG produced by the foetus diffuses from the foetal vessels to the villi and is then secreted through the syncytiotrophoblast lining to the placental intervillous space [54]. Characterisation of CSPGs has isolated molecules with important immunmodulatory functions. A CSPG called versican binds to chemokines such as macrophage inflammatory protein and monocyte chemoattractant protein [106]. Levels of CSPG are raised markedly during falciparum infection in the placenta, indicating a defensive role [54]. This shows that CSPG molecules are important to the foetus and may not be a direct target for intervention.

\section{Competitive Inhibition of Binding Site with CSA?}

CSA receptors undergo very little variation in their recognition sites, certainly in comparison to VSAs [29]. Therefore, would it not be possible to generate molecules with an embedded CSA receptor using proteomics technology? Following first recognition of pregnancy, these molecules could be administered to the female. At the placenta, the artificial CSA could be bound by the VSAs on infected erythrocytes. The artificial CSA would compete for binding, thereby preventing infected erythrocytes from sequestering at the placenta. The free CSA/VSA complexes would generate an immune response and be cleared by filtration through the spleen. An additional advantage would be the inevitable adherence of some infected erythrocytes to placental CSA. This would allow the maintenance of the natural immune response but be insufficient to generate harmful effects.

Beeson et al., [53] demonstrated that the application of CSA fragments did inhibit the adhesion of parasites to CSA by competitive binding. They used protein digestion to attain a variety of fragments and found binding inhibition to be size-dependent, whereby a tetradecasaccharide segment was the minimum length required [53]. The level of inhibition was highly dose-dependent with a saturation point. Encouragingly, Pouvelle et al., [107] showed that in a monkey model infected with CSA-binding $P$. falciparum, injection of CSA fragments successfully reversed parasite sequestration. On a practical level, Conte et al., [108] demonstrated the safe administration of CSA fragments to human subjects by both oral and intravenous route.

In order to use CSA fragments therapeutically, the point at which CSA should be administered needs to be determined, i.e. during early pregnancy or even before conception. Since infected erythrocytes bound to artificial CSA will be cleared by the immune system, would repeat doses of CSAs be needed and at what intervals? Alternatively, intervention with CSA fragments could be required only for women in their first pregnancies, with naturally acquired immunity developing concurrently to protect them in later pregnancies.

\section{Modelling the CSA-binding Pocket}

Duffy et al., [109] advocated the use of functional genomics and proteomics to model PAM vaccine candidates. Subsequent work to develop novel malaria drug treatments has employed the use of X-ray crystallography to study the sites of interaction between parasitic antigen and host cell receptors [110]. X-ray crystallography uses X-rays to scatter the electrons of the subject, which are held within a crystal. The pattern produced enables a 3-dimensional construct to be generated. Visualising the crystal structures of the VSA/CSA bound complexes would enable their recognition sites to be mapped. This would help in the rational design of a vaccine to inhibit the binding of VSA to CSA sitting in the CSA-binding pocket which prevents VSA access.

\section{Therapeutic Antibodies}

If the antibodies that develop through natural immunity were characterised, it may be possible to deliver them therapeutically to the primigravid [34]. If antibody administration were to take place early in pregnancy this could close the window of opportunity for placental sequestration. In support of this intervention, Costa et al., [111] found that in a cytoadhesion assay a monoclonal antibody induced the release of infected erythrocytes from the placenta. This de-sequestration occurred in a dosedependent fashion, thereby strengthening the case for antibodies to be used as immunotherapy. However, the dose of antibodies required to be given to a pregnant woman or the safety of this method in terms of generating an adverse immune response are unknown. It needs to be established which antibodies are pan-reactive to diverse global isolates. There may be logistical problems since women in rural sub-Saharan Africa may not have contact with a health professional during the very early stages of their pregnancies.

\section{Gene knock-outs: Is it Possible to 'Switch off' Variation?}

A new and exciting area of research involves elucidating further information about the genes of the parasite which encode its antigenic switching. Antigenic switching alters the gene expression within a single parasite. Since there is only 
one var2CSA in the parasite's genome, switching would mean rendering the var2CSA epitope either 'on' or 'off'. In vitro studies have revealed that antigenic switching in $P$. falciparum may reach up to $2 \%$ per generation [112]. The molecular triggers for antigenic switching remain poorly understood.

It seemed plausible that a var gene promoter in an episomal plasmid acts as a trans-acting factor influencing var gene expression [29]. However, this promoter remains permanently active regardless of the status of var gene expression, indicating that there must be other mediating factors. It appears likely that gene expression is controlled by epigenetic factors, since switching of var type occurs in situ without underlying changes in the DNA sequence of the organism [113]. An example of an epigenetic factor is histone protein, which has an important function in associating DNA into nucleosomes, which are packaged into chromatin fibres. At the chromosomal telomere is a gene promoter named $P$. falciparum silent information regulator 2 (PfSir2). When a particular var gene is to be expressed, the PfSir2 protein is moved away from the promoter region [114]. This stimulates the acetylation of histone which can undergo reversible modification and thereby alter gene expression, suggesting this as a possible mechanism for monoallelic var gene expression [114]. Therefore, the expression of a particular var gene is related to its position in chromatin regions, whereby subtelomeric var genes are switched on in PfSir2 mutant parasites, whereas var genes located in central chromosomal regions remain silent [114].

Voss et al., [115] propose the existence of a var promoter which induces the spread of silenced chromatin. This group demonstrated that the var promoter uses an additional piece of genetic sequence which, when activated, is able to silence var gene transcription [115]. They produced a mutated isolate of $P$. falciparum containing the gene encoding resistance to the drug blasticidin-S. The activation of the gene can be measured by growing parasites in a culture medium containing the blasticidin-S, and measuring susceptibility to the drug. It was concluded that the upstream sequence $\mathrm{C}$ (upsC), which is found in chromosome internal clusters and flanks var genes, is the vital var gene promoter which maintains non-expression of the var genes. Therefore, the silenced state is the var gene 'default' position, with a specific event enabling the expression of one variant. Voss et al., [115] hypothesised that there is only one specific recognition site which activates transcription of the var gene present in the site. Therefore, which var variant is expressed is dependent upon var promoter competition for this compartment.

The research of Voss et al., [115] culminated in the successful 'switching off' of transcription of endogenous var genes. This work could have a potentially huge impact on malaria vaccine development since researchers could control the level of var gene expression, thereby suppressing the antigenic variation of PfEMP-1 molecules. A purely speculative scenario could involve prophylactic administration of one vaccine containing a known VSA sequence in order to stimulate the immune response to this var gene product. Upon pregnancy, could a second preparation be given, containing molecules to mediate var gene switching, effectively standardising gene expression and rendering these infected erythrocytes recognisable to the primed immune system? Considerable further research needs to be performed to determine how this technology could be utilised for developing protective tools to be used in vivo.

\section{VSA-based Vaccines}

The success of a VSA-based vaccine depends upon determining the antigens which are critical for generating a pan-reactive antibody response. In light of the debate over the relative importance of var1CSA and var2CSA in generating a CSA-binding phenotype, research continues to determine whether these or any additional ligands are involved.

Although the bulk of current evidence points towards var2CSA as the dominant ligand, there is still uncertainty since the anti-DBL3 $\gamma$ molecules of var1CSA have been shown to inhibit binding to CSA. This was demonstrated in 2002 by Lekana Douki et al., [116] who tolerised murine B cells to human erythrocytes with a CSA-binding phenotype. Chinese hamster ovary cells were used as a medium with which to inject the mice with a DBL $\gamma 3$ domain, which led to the development of monoclonal antibodies. These antibodies were isolated and found to inhibit the binding of CSA by parasite isolates from around the world. In a similar study, Costa et al., [111] immunised a monkey model with recombinant DBL $\gamma 3$ and raised antibodies against this antigen which inhibited the binding of a variety of parasite strains with different genotypes. These antibodies were also pan-reactive to parasites from various geographical locations. The quantitative similarity in parasite inhibition that occurs in sera from monkeys immunised with DBL $\gamma 3$ compared to sera from multigravid women supposed that the immunity conferred by the epitope is of a level similar to that of the multigravid state [111].

A paradox therefore exists whereby DBL $\gamma 3$ elicits the desired protective antibody response when administered to mice although the leading vaccine candidate var2CSA does not encode a protein with a DBL $\gamma$ domain. Bir et al., [117] addressed this issue by selecting parasites for binding to CSA and found that var2CSA is the major expressed PfEMP-1. The DBL2X and DBL3X domains were seen to bind to CSA during the assay. Sera containing antibodies to the DBL $\gamma 3$ domains of var1CSA-encoded antigens were found to inhibit DBL3X from binding to CSA. This demonstrates cross-reactivity between the domains of var1CSA- and var2CSA-encoded VSAs, suggesting the presence of $\mathrm{B}$ cell epitopes which are common to both DBL domains. This level of cross-reactivity provides an explanation as to how both gene products are able to bind CSA. In the opinion of Scherf et al., [102], if the DBL CSA binding domain of var1CSA can induce cross-reactive antibodies against var2CSA (which seems to be the case), this option should also be analysed. However, when discussing this same issue, Hviid states that few researchers consider VAR1 as a serious candidate anymore and that at least as far as the PfEMP1 family is concerned var2CSA is currently the only credible candidate [118].

In further support of the var2CSA candidate, Avril et al., [42] raised successfully in a mouse model monoclonal antibodies against domains of var2CSA which inhibited up 
to $60 \%$ of adhesion between VSAs and CSA. The domains

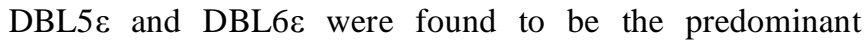
antigenic targets of the antibodies, although half of the antibodies also responded to DBL2x or DBL3x. The crossreactivity of antibody response to different domains of var2CSA gene product is likely to be due to the $30.5 \%$ shared sequence identity between DBL5 $\varepsilon$ and DBL6 $\varepsilon$ [42]. Between DBL2x and DBL3x, there is little commonality in sequence, suggesting that the similarity between these domains is conformational. The parasitic ligands recognised by monoclonal antibodies were isolated, purified and administered to mice. After a third immunisation, antibodies developed against CSA-binding parasites. The sera from these immunised mice were re-isolated and found to inhibit binding to CSA in vitro, exhibiting the effectiveness of antibody response generated in the mouse model [42]. This study clearly presents specific domains of the candidate antigen var2CSA that should be considered for inclusion in a vaccine. Similarly, in 2004 Salanti et al., [119] elicited the production of cross-reactive antibodies raised against corresponding domains of var2CSA. Their successful protocol involved inserting the var gene encoding DBL5\& into a baculovirus. The baculovirus expressed the DBL5\& protein, which stimulated a mouse antibody response [119]. Hence, recombinant proteins should be investigated as a potential route of vaccine administration for PAM.

This rather neat conclusion of a small number of conserved and structurally similar domains as vaccine targets sits rather uncomfortably with the extent of antigenic diversity mentioned previously. However, these two arguments can be reconciled due to the unusual genomic structure of the var genes. As discussed with reference to antigenic variation, the location of the var genes at the chromosomal telomere determines their expression. Clustering of several chromosome ends in $P$. falciparum facilitates alignment of homologous sequences located on heterologous chromosomes which may create a recombination 'hot spot' by means of gene conversion among the var genes [102]. In contrast, Costa et al., [111] found that the subtelomeric varCSA gene is transcribed in a direction opposite to that of the telomere-adjacent var genes, indicating that this gene is unlikely to undergo gene conversion with other var genes. Thus, the unusual genomic organisation of var1CSA and var2CSA may account for their high level of conservation.

\section{METHODS OF DELIVERING A PAM VACCINE}

Having isolated the designated antigen(s) it remains to be established by what means this vaccine can be administered safely and effectively. A promising route of development involves using subunit vaccines. These may comprise recombinant proteins, i.e. the antigens themselves, which can be administered directly to stimulate an immune response [120]. However, the administration of antigens alone has often resulted in poor immunogenicity. Accurate conformation of antigens is of particular importance for receptor recognition. Ensuring this is maintained throughout manufacture can be tricky, time consuming and consequently expensive [121]. Special care would be required with recombinant proteins during global transportation and in finding suitable conditions for stable storage [121].
The experimental techniques of DNA vaccines or viral vectors provide an alternative strategy. A DNA vaccine involves using the DNA sequence which encodes the antigen protein. Plasmids are rings of extra-chromosomal DNA material which can be extracted from bacteria and used to carry the desired DNA. The plasmid containing the DNA may be administered directly or an attenuated bacterium or virus-infected cell may be transfected with the plasmid and inoculated. Alternatively, a sample of the patient's own cells can be removed, transfected with the plasmid and then reimplanted [122].

Once administered to the recipient's cells, transcription factors in the host cell nucleus recognise the promoter included on the plasmid. This initiates the processes of transcription and translation that result in protein antigen formation. A transcription terminator is also present on the plasmid to ensure transcription of only the antigenic gene products by the host cell machinery. The antigens migrate to the cytoplasmic membrane where they are presented on the surface with an MHC molecule. This stimulates $\mathrm{T}$ cell responsiveness, leading to development of an effective immune response against PAM antigens. If a naked DNA vaccine was injected into muscle, these cells would also express the antigens on their surface [122]. These cells would be recognised by antigen-presenting cells, triggering $\mathrm{B}$ and $\mathrm{T}$ cell responses [120].

An advantage of some viral vectors for DNA vaccines is their capacity to carry more than one gene [121]. This could allow researchers to equip the vector with the DNA encoding several var1CSA and var2CSA sequences in a multi-epitope string. The manufacturing and processing costs would be relatively modest given that a standard protocol for viral vector vaccine production could be used [121].

Viral vectors used for vaccine research include the modified vaccinia virus Ankara (MVA) [123]. The virus is rendered incapable of replication inside human cells by attenuation but is still strongly immunogenic. Adenoviruses may be utilised as vectors due to the potent immune responses which they induce. However, their usage is complicated by the high level of anti-vector immunity that is observed in Africa due to prior exposure to adenoviruses during respiratory tract infections [123].

Using these vaccines alone may not produce a sufficient immune response to confer long-lasting protection against PAM [124]. Therefore, a 'primer' of naked antigen DNA could be provided to stimulate the initial immune response. After an interval this could be followed by a 'booster' immunisation administered via a vector, which may contain different or additional antigens [120]. The second wave of chosen antigens to be presented should confer lasting protection against a wild-type challenge, through the development of memory B cells. The response to vaccination can be measured by quantitative analysis of the production of IFN- $\gamma$ by $\mathrm{T}$ cells. DNA vaccination followed by MVA immunisation yields the strongest immune response [123].

Immunity to $P$. berghei in mice was successfully achieved by priming with plasmid DNA encoding a liver stage antigen. This was followed by a booster of vaccinia virus, modified to contain the DNA of the Plasmodium antigen, resulting in complete immunity to the parasite [125]. 
Subsequently, Lekana Douki et al., [116] inserted a DBL $\gamma$ domain of P. falciparum into an Escherichia coli fusion protein. Antibodies were produced in the mice, guinea pigs and rabbits inoculated with the E. coli proteins. However, when isolated, these antibodies were unable to bind to CSAbinding infected erythrocytes. This emphasises the importance of conformational epitopes in the natural immune response to the surface of infected erythrocytes [116]. Researchers therefore need to ensure that the gene product of the vaccine antigen DNA has the same conformation as that of the protein expressed by wild-type strains.

Further research is required in the development of these models of immunisation for use in PAM, assessing different combinations of var1CSA and var2CSA antigens for their relative effectiveness.

\section{CONCLUSION}

This review has discussed the development of the placenta, its exploitation by the malaria parasite and how this generates pathological changes during infection. Following repeated exposure to unique CSA-binding parasites over successive pregnancies a female can enter a state of semiimmunity to PAM. This accounts for the inverse relationship between increasing gravidity and clinical disease.

The protective antibodies which develop following cumulative parasite exposure are pan-reactive to isolates from around the world. This strengthens the hopes for a vaccine, which would aim to generate artificially this immune response. This contradicts the pronounced variation of the var genes and the antigens which they encode. Bockhorst et al., [99] proposed the existence of a var gene mosaic of conserved and variant regions. Consequently, it seems likely that the divergent var sequences encode VSAs which have sufficient similarity in pattern to be recognised globally. However, it remains to be seen whether this recognition by the immune system is due to a highly conserved epitope in all sequences or to a repertoire of antibodies produced to a wider pool of variants.

Generation of a successful vaccine may require the use of more than one antigenic sequence. The current leading candidates are var1CSA and var2CSA and it has been suggested that both antigens could be administered together in a single vaccine [126]. Further to delineation of candidate antigen(s), work in coming years will need to establish how best they can be delivered, perhaps through a combination of recombinant proteins and viral vectors.

At this point there are many puzzling issues left unsolved and until these paradoxes have been addressed, a vaccine will not be forthcoming. Such questions include:

- Does the binding of infected erythrocytes to IgM have a significant role in parasite immune evasion and would this impact upon vaccine efficacy?

- Are there any further parasitic ligands involved in binding to the placenta and what is their relative significance?

- Would the use of a single highly conserved sequence or a cocktail of allelic parasite forms be more efficient in generating a protective immune response?
- Is the var2CSA epitope sufficient to generate protection against clinical disease once administered?

- Can researchers develop an adjuvant to be given with recombinant proteins, to generate a strong immune response?

- What is the role of opsonising antibodies in maternal immunity to PAM and could they be used in a vaccine?

- Is there a finite range of var gene variation? Would the selection pressure of a vaccine only increase the variation?

- Could understanding the mechanisms of parasite antigenic switching lead to therapeutic strategies to impair this process and prevent the generation of variation?

- When in a woman's life should a vaccine designed to protect during first pregnancy be given?

- Is there adequate public health infrastructure to ensure efficient administration of a PAM vaccine in sub-Saharan Africa?

The process of developing a vaccine to elicit protective effects during pregnancy is complicated by the complex interaction between the maternal immune system and the foetal allograft. For example, Costa et al., [37] advocated that a PAM vaccine should contain elements to induce significant IFN- $\gamma$ secretion by $\mathrm{T}$ cells. This approach may indeed induce a strong cell-mediated immune response. However, high levels of IFN- $\gamma$ are harmful to the foetus, suggesting that this cytokine should not be overtly stimulated by a vaccine unless the effects on the foetus have been characterised fully. Therefore, even if a seemingly effective vaccine is produced in the next few years, it will require rigorous testing in animal models followed by many careful clinical trials. Advancements are occurring rapidly in this field of research, although due to the delicate balance of the immune response during pregnancy, the rational design of a PAM vaccine will always require a cautious approach.

A VAR1CSA or VAR2CSA vaccine would be limited in its protective target group. Women who lack naturally acquired immunity are not protected from peripheral binding variants and immunisation would not inhibit binding of these parasites, resulting in peripheral infection. Furthermore, selection pressure exerted by such a vaccine is likely to increase global antigenic diversity. Continued efforts to identify conserved epitopes are the aim of non-PAM vaccines and proof of principle studies have led to phase III trials (reviewed in [127]). The most advanced candidate, the RTS,S vaccine against the circumsporozoite antigen, provided $25.6-59 \%$ protection in phase II trials and became the first malaria vaccine to reach phase III trials [128]. While this extensive study across seven sub-Saharan countries will not be completed before 2014, preliminary results show grounds for qualified optimism $[129,130]$. It is unclear what protection this may provide during pregnancy because it is unlikely to achieve sterile immunity and despite women having antibodies against non-VSAPAM and other parasite proteins prior to pregnancy, the immunity that develops is not adequate to prevent pregnancy-associated infection. 
Given the difficulties in vaccine design that have been encountered to date, it would be easy for researchers to lose sight of why a vaccine would be such an important development. An effective vaccine, successfully implemented, would prevent suffering and reduce the need for chemotherapeutics, as demonstrated by the eradication of small pox and near-eradication of polio [122]. In today's climate of extensive resistance to anti-malarial chemotherapy, coinfection with HIV and increasing migration of populations, the development of a malaria vaccine is of paramount importance. The further significant input of finance, time and effort required to turn current knowledge of immunopathology into a viable vaccine is considerable. However, sufficient progress has already been made to indicate that synergy between laboratory and field research could culminate in a PAM vaccine, preventing the deaths of up to 10,000 mothers and up to 200,000 infants annually in subSaharan Africa.

\section{CONFLICT OF INTEREST}

Declared none.

\section{ACKNOWLEDGEMENTS}

Financial support: University of Leeds (grant number DEV.BIOL.319190 to AWTR). Professors David Conway (Medical Research Council Laboratories, The Gambia), Lars Hviid (University of Copenhagen), Artur Scherf (Institut Pasteur, Paris) and Drs Sue Kyes (University of Oxford) and Joseph Smith (Seattle Biomedical Research Institute) are thanked for their correspondence providing constructive comments on our suggestions and clarification of detailed queries regarding their published research.

\section{REFERENCES}

[1] Roberts, D.J. Understanding naturally acquired immunity to Plasmodium falciparum malaria. Infect. Immun., 2003, 71(2), 589590.

[2] McGregor, I.A. Epidemiology, malaria and pregnancy. Am. $J$. Trop. Med. Hyg., 1984, 33(4), 517-525.

[3] Steketee, R.W.; Nahlen, B.L.; Parise, M.E.; Menendez, C. The burden of malaria in pregnancy in malaria-endemic areas. Am. $J$. Trop. Med. Hyg., 2001, 64(Suppl 1-2), 28-35.

[4] Guyatt, H.L.; Snow, R.W. The epidemiology and burden of Plasmodium falciparum-related anemia among pregnant women in sub-Saharan Africa. Am. J. Trop. Med. Hyg., 2001, 64(Suppl 1-2), $36-44$.

[5] van Geertruyden, J.P.; Thomas, F.; Erhart, A.; D'Alessandro, U. The contribution of malaria in pregnancy to perinatal mortality. Am. J. Trop. Med. Hyg., 2004, 71(Suppl 2), 35-40.

[6] Guyatt, H.L.; Snow, R.W. Malaria in pregnancy as an indirect cause of infant mortality in sub-Saharan Africa. Trans. R. Soc. Trop. Med. Hyg., 2001, 95(6), 569-576.

[7] Taylor-Robinson, A.W. A model of development of acquired immunity to malaria in humans living under endemic conditions. Med. Hypotheses, 2002, 58(2), 148-56.

[8] Martens, P.; Hall, L. Malaria on the move: human population movement and malaria transmission. Emerg. Infect. Dis., 2000, 6(2), 103-109.

[9] Gilles, H.M.; Warrell, D.A. The Malaria Parasites. In: Essential Malariology, $4^{\text {th }}$ ed.; Gilles, H.M.; Warrell, D.A, Eds.; Hodder Arnold: London, 2002; pp. 8-34.

[10] Chitnis, C.E.; Blackman, M.J. Host cell invasion by malaria parasites. Parasitol. Today, 2000, 16(10), 411-415.

[11] Egan, T.J.; Combrinck, J.M.; Egan, J.; Hearne, G.R.; Marques, H.M.; Ntenteni, S.; Sewell, B.T.; Smith, P.J.; Taylor, D.; van Schalkwyk, D.A.; Walden, J.C. Fate of haem iron in the malaria parasite Plasmodium falciparum. Biochem. J., 2002, 365(2), 343-347.

[12] Luppi, P. How immune mechanisms are affected by pregnancy. Vaccine, 2003, 21(24), 3352-3357.

[13] Wegmann, T.G.; Lin, H.; Guilbert, L.; Mosmann, T.R. Bidirectional cytokine interactions in the maternal-fetal relationship: is successful pregnancy a TH2 phenomenon? Immunol. Today, 1993, 14(7), 353-356.

[14] Silen, M.L.; Firpo, A.; Morgello, S.; Lowry, S.F.; Francus, T. Interleukin-1 alpha and tumor necrosis factor alpha cause placental injury in the rat. Am. J. Pathol., 1989, 135(2), 239-244.

[15] Romero, R.; Mazor, M.; Tartakovsky, B. Systemic administration of interleukin-1 induces preterm parturition in mice. Am. J. Obstet. Gynecol., 1991, 165(4), 969-971.

[16] Lin, H.; Mosmann, T.R.; Guilbert, L.; Tuntipopipat, S.; Wegmann, T.G. Synthesis of T helper 2-type cytokines at the maternal-fetal interface. J. Immunol., 1993, 151(9), 4562-4573.

[17] Aagaard-Tillery, K.M.; Silver, R.; Dalton, J. Immunology of normal pregnancy. Semin. Fetal Neonatal Med., 2006, 11(5), 279-295.

[18] Piccinni, M.P.; Giudizi, M.G.; Biagiotti, R.; Beloni, L.; Giannarini, L.; Sampognaro, S.; Parronchi, P.; Manetti, R.; Annunziato, F.; Livi, C.; Progesterone favors the development of human T helper cells producing Th2-type cytokines and promotes both IL-4 production and membrane CD30 expression in established Th1 cell clones. J. Immunol., 1995, 155(1), 128-133.

[19] Ashkar, A.A.; Di Santo, J.P.; Croy, B.A. Interferon gamma contributes to initiation of uterine vascular modification, decidual integrity, and uterine natural killer cell maturation during normal murine pregnancy. J. Exp. Med., 2000, 192(2), 259-270.

[20] Svensson, L.; Arvola, M.; Sällström, M.A.; Holmdahl. R.; Mattsson, R. The Th2 cytokines IL-4 and IL-10 are not crucial for the completion of allogeneic pregnancy in mice. J. Reprod. Immunol., 2001, 5l(1), 3-7.

[21] Luppi, P.; Haluszczak, C.; Betters, D.; Richard, C.A.; Trucco, M.; DeLoia, J.A. Monocytes are progressively activated in the circulation of pregnant women. J. Leukoc. Biol., 2002, 72(5), 874-884.

[22] Lila, N.; Rouas-Freiss, N.; Dausset, J.; Carpentier, A.; Carosella, E.D. Soluble HLA-G protein secreted by allo-specific $\mathrm{CD}^{+} \mathrm{T}$ cells suppresses the allo-proliferative response: a $\mathrm{CD} 4^{+} \mathrm{T}$ cell regulatory mechanism. Proc. Natl. Acad. Sci. USA, 2001, 98(21), 1215012155.

[23] Artavanis-Tsakonas, K.; Tongren, J.E.; Riley, E.M. The war between the malaria parasite and the immune system: immunity, immunoregulation and immunopathology. Clin. Exp. Immunol., 2003, 133(2), 145-152.

[24] Oehler, L.; Kollars, M.; Bohle, B.; Berer, A.; Reiter, E.; Lechner, K.; Geissler, K. Interleukin-10 inhibits burst-forming unit-erythroid growth by suppression of endogenous granulocyte-macrophage colony-stimulating factor production from T cells. Exp. Hematol., 1999, 27(2), 217-223.

[25] Fried, M.; Muga, R.O.; Misore, A.O.; Duffy, P.E. Malaria elicits type 1 cytokines in the human placenta: IFN- $\gamma$ and TNF- $\alpha$ associated with pregnancy outcomes. J. Immunol., 1998, 160(5), 2523-2530.

[26] Young, I.R. The comparative physiology of parturition in mammals. Front. Horm. Res., 2001, 27(10), 10-30.

[27] Achur, R.N.; Valiyaveettil, M.; Alkhalil, A.; Ockenhouse, C.F.; Gowda, D.C. Characterization of proteoglycans of human placenta and identification of unique chondroitin sulfate proteoglycans of the intervillous spaces that mediate the adherence of Plasmodium falciparum-infected erythrocytes to the placenta. J. Biol. Chem., 2000, 275(51), 40344-40356.

[28] Duffy, P.E.; Fried, M. Malaria in the pregnant woman. Curr. Top. Microbiol. Immunol., 2005, 295(1), 169-200.

[29] Kyes, S.; Horrocks, P.; Newbold, C. Antigenic variation at the infected red cell surface in malaria. Anпи. Rev. Microbiol., 2001 , 55(1), 673-707.

[30] Miller, L.H.; Baruch, D.I.; Marsh, K.; Doumbo, O.K. The pathogenic basis of malaria. Nature, 2002, 415(6872), 673-679.

[31] Leech, J.H.; Barnwell, J.W.; Aikawa, M.; Miller, L.H.; Howard, R.J. Plasmodium falciparum malaria: association of knobs on the surface of infected erythrocytes with a histidine-rich protein and the erythrocyte skeleton. J. Cell. Biol., 1984, 98(4), 1256-1264. 
[32] Sharling, L.; Enevold, A.; Sowa, K.M.; Staalsoe, T.; Arnot, D.E. Antibodies from malaria-exposed pregnant women recognize trypsin resistant epitopes on the surface of Plasmodium falciparuminfected erythrocytes selected for adhesion to chondroitin sulphate A. Malar. J., 2004, 3, 31 .

[33] Rowe, J.A.; Kyes, S.A. The role of Plasmodium falciparum var genes in malaria in pregnancy. Mol. Microbiol., 2004, 53(4), 1011-1019.

[34] Gamain, B.; Smith, J.D.; Viebig, N.K.; Gysin, J.; Scherf, A. Pregnancy-associated malaria: parasite binding, natural immunity and vaccine development. Int. J. Parasitol., 2007, 37(3-4), 273283.

[35] Fried, M.; Duffy, P.E. Adherence of Plasmodium falciparum to chondroitin sulfate $\mathrm{A}$ in the human placenta. Science, 1996, 272(5267), 1502-1504.

[36] Gamain, B.; Gratepanche, S.; Miller, L.H.; Baruch, D.I. Molecular basis for the dichotomy in Plasmodium falciparum adhesion to CD36 and chondroitin sulfate A. Proc. Natl. Acad. Sci. USA, 2002, 99(15), 10020-10024.

[37] Costa, F.T.; Avril, M.; Nogueira, P.A.; Gysin, J. Cytoadhesion of Plasmodium falciparum-infected erythrocytes and the infected placenta: a two-way pathway. Braz. J. Med. Biol. Res., 2006, 39(12), 1525-1536.

[38] Fried, M.; Domingo, G.J.; Gowda, C.D.; Mutabingwa, T.K.; Duffy, P.E. Plasmodium falciparum: chondroitin sulfate $\mathrm{A}$ is the major receptor for adhesion of parasitized erythrocytes in the placenta. Exp. Parasitol., 2006, 113(1), 36-42.

[39] Baruch, D.I.; Pasloske, B.L.; Singh, H.B.; Bi, X.; Ma, X.C.; Feldman, M.; Taraschi, T.F.; Howard, R.J. Cloning the $P$. falciparum gene encoding PfEMP1, a malarial variant antigen and adherence receptor on the surface of parasitized human erythrocytes. Cell, 1995, 82(1), 77-87.

[40] Su, X.Z.; Heatwole, V.M.; Wertheimer, S.P.; Guinet, F.; Herrfeldt, J.A.; Peterson, D.S.; Ravetch, J.A.; Wellems, T.E. The large diverse gene family var encodes proteins involved in cytoadherence and antigenic variation of Plasmodium falciparum-infected erythrocytes. Cell, 1995, 82(1), 89-100.

[41] Buffet, P.A.; Gamain, B.; Scheidig, C.; Baruch, D.; Smith, J.D.; Hernandez-Rivas, R.; Pouvelle, B.; Oishi, S.; Fujii, N.; Fusai, T.; Parzy, D.; Miller, L.H.; Gysin, J.; Scherf, A. Plasmodium falciparum domain mediating adhesion to chondroitin sulfate A: a receptor for human placental infection. Proc. Natl. Acad. Sci. USA, 1999, 96(22), 12743-12748.

[42] Avril, M.; Gamain, B.; Lépolard, C.; Viaud, N.; Scherf, A.; Gysin, J. Characterization of anti-var2CSA-PfEMP1 cytoadhesion inhibitory mouse monoclonal antibodies. Microbes Infect., 2006, 8(14-15), 2863-2871.

[43] Jensen, A.T.; Zornig, H.D.; Buhmann, C.; Salanti, A.; Koram, K.A.; Riley, E.M.; Theander, T.G.; Hviid, L.; Staalsoe, T. Lack of gender-specific antibody recognition of products from domains of a var gene implicated in pregnancy-associated Plasmodium falciparum malaria. Infect. Immun., 2003, 71(7), 4193-4196.

[44] Andrews, K.T.; Pirrit, L.A.; Przyborski, J.M.; Sanchez, C.P.; Sterkers, Y.; Ricken, S.; Wickert, H.; Lépolard, C.; Avril, M.; Scherf, A.; Gysin, J.; Lanzer, M. Recovery of adhesion to chondroitin-4-sulphate in Plasmodium falciparum varCSA disruption mutants by antigenically similar PfEMP1 variants. Mol. Microbiol., 2003, 49(3), 655-669.

[45] Viebig, N.K.; Gamain, B.; Scheidig, C.; Lépolard, C.; Przyborski, J.; Lanzer, M.; Gysin, J.; Scherf, A. A single member of the Plasmodium falciparum var multigene family determines cytoadhesion to the placental receptor chondroitin sulphate A. EMBO Rep., 2005, 6(8), 775-781.

[46] Salanti, A.; Staalsoe, T.; Lavstsen, T.; Jensen, A.T.; Sowa, M.P.; Arnot, D.E.; Hviid, L.; Theander, T.G. Selective upregulation of a single distinctly structured var gene in chondroitin sulphate Aadhering Plasmodium falciparum involved in pregnancy-associated malaria. Mol. Microbiol., 2003, 49(1), 179-191.

[47] Beeson, J.G.; Brown, G.V. Plasmodium falciparum-infected erythrocytes demonstrate dual specificity for adhesion to hyaluronic acid and chondroitin sulfate $\mathrm{A}$ and have distinct adhesive properties. J. Infect. Dis., 2004, 189(2), 169-179.

[48] O'Neil-Dunne, I.; Achur, R.N.; Agbor-Enoh, S.T.; Valiyaveettil, M.; Naik, R.S.; Ockenhouse, C.F.; Zhou, A.; Megnekou, R.; Leke, R.; Taylor, D.W.; Gowda, D.C. Gravidity-dependent production of antibodies that inhibit binding of Plasmodium falciparum-infected erythrocytes to placental chondroitin sulfate proteoglycan during pregnancy. Infect. Immun., 2001, 69(12), 7487-7492.

[49] Gysin, J.; Pouvelle, B.; Le Tonquèze, M.; Edelman, L.; Boffa, M.C. Chondroitin sulfate of thrombomodulin is an adhesion receptor for Plasmodium falciparum-infected erythrocytes. Mol. Biochem. Parasitol., 1997, 88(1-2), 267-271.

[50] Muthusamy, A.; Achur, R.N.; Bhavanandan, V.P.; Fouda, G.G.; Taylor, D.W.; Gowda, D.C. Plasmodium falciparum-infected erythrocytes adhere both in the intervillous space and on the villous surface of human placenta by binding to the low-sulfated chondroitin sulfate proteoglycan receptor. Am. J. Pathol., 2004, 164(6), 2013-2025.

[51] Beeson, J.G.; Rogerson, S.J.; Cooke, B.M.; Reeder, J.C.; Chai, W.; Lawson, A.M.; Molyneux, M.E.; Brown, G.V. Adhesion of Plasmodium falciparum-infected erythrocytes to hyaluronic acid in placental malaria. Nat. Med., 2000, 6(1), 86-90.

[52] Smith, J.D.; Miller, L.H. Infected erythrocyte binding to hyaluronic acid and malaria in pregnant women. J. Infect. Dis., 2004, 189(2), $165-168$

[53] Beeson, J.G.; Chai, W.; Rogerson, S.J.; Lawson, A.M.; Brown, G.V. Inhibition of binding of malaria-infected erythrocytes by a tetradecasaccharide fraction from chondroitin sulfate A. Infect. Immun., 1998, 66(7), 3397-3402.

[54] Muthusamy, A.; Achur, R.N.; Valiyaveettil, M.; Botti, J.J.; Taylor, D.W.; Leke, R.F.; Gowda, D.C. Chondroitin sulfate proteoglycan but not hyaluronic acid is the receptor for the adherence of Plasmodium falciparum-infected erythrocytes in human placenta, and infected red blood cell adherence up-regulates the receptor expression. Am. J. Pathol., 2007, 170(6), 1989-2000.

[55] Okoko, B.J.; Enwere, G.; Ota, M.O. The epidemiology and consequences of maternal malaria: a review of immunological basis. Acta Trop., 2003, 87(2), 193-205.

[56] Archibald, H.M. The influence of malarial infection of the placenta on the incidence of prematurity. Bull. World Health Organ., 1956, 15(3-5), 842-845.

[57] Fried, M.; Nosten, F.; Brockman, A.; Brabin, B.J.; Duffy, P.E. Maternal antibodies block malaria. Nature, 1998, 395(6705), 851-852.

[58] Brabin, B.J. An analysis of malaria in pregnancy in Africa. Bull. World Health Organ., 1983, 61(6), 1005-1016.

[59] Elliott, S.R.; Brennan, A.K., Beeson, J.G.; Tadesse, E.; Molyneux, M.E.; Brown, G.V.; Rogerson, S.J. Placental malaria induces variantspecific antibodies of the cytophilic subtypes immunoglobulin G1 (IgG1) and $\mathrm{IgG} 3$ that correlate with adhesion inhibitory activity. Infect. Immun., 2005, 73(9), 5903-5907.

[60] Rowe, J.A.; Shafi, J.; Kai, O.K.; Marsh, K.; Raza, A. Nonimmune IgM, but not IgG binds to the surface of Plasmodium falciparuminfected erythrocytes and correlates with rosetting and severe malaria. Am. J. Trop. Med. Hyg., 2002, 66(6), 692-699.

[61] Semblat, J.P.; Raza, A.; Kyes, S.A.; Rowe, J.A. Identification of Plasmodium falciparum var1CSA and var2CSA domains that bind IgM natural antibodies. Mol. Biochem. Parasitol., 2006, 146(2), 192-197.

[62] Creasey, A.M.; Staalsoe, T.; Raza, A.; Arnot, D.E.; Rowe, J.A. Non-specific immunoglobulin $\mathrm{M}$ binding and chondroitin sulfate A binding are linked phenotypes of Plasmodium falciparum isolates implicated in malaria during pregnancy. Infect. Immun., 2003, 71(8), 4767-4771.

[63] Mina-Osorio, P.; Ortega, E. Signal regulators in FcR-mediated activation of leukocytes? Trends Immunol., 2004, 25(10), 529535.

[64] Alvarez, J.R.; Al-Khan, A.; Apuzzio, J.J. Malaria in pregnancy. Infect. Dis. Obstet. Gynecol., 2005, 13(4), 229-236.

[65] Looareesuwan, S.; Phillips, R.E.; White, N.J.; Kietinun, S.; Karbwang, J.; Rackow, C.; Turner, R.C.; Warrell, D.A. Quinine and severe falciparum malaria in late pregnancy. Lancet, 1985, 2(8445), 4-8.

[66] Dorman, E.K.; Shulman, C.E. Malaria in pregnancy. Curr. Obstet. Gynaecol., 2000, 10(4), 183-189.

[67] Hanretty, K.P. Obstetrics Illustrated, $7^{\text {th }}$ ed. Churchill Livingstone: Edinburgh, 2009.

[68] Shulman, C.E.; Marshall, T.; Dorman, E.K.; Bulmer, J.N.; Cutts, F.; Peshu, N.; Marsh, K. Malaria in pregnancy: adverse effects on haemoglobin levels and birthweight in primigravidae and multigravidae. Trop. Med. Int. Health, 2001, 6(10), 770-778. 
[69] Dundas, K. Obstetrics - the physiological changes. Hosp. Pharm., 2003, 10(5), 242-254.

[70] Umbers, A.J.; Aitken, E.H.; Rogerson, S.J. Malaria in pregnancy: small babies, big problem. Trends Parasitol., 2011, 27(4), 168-175.

[71] Murphy, S.C.; Breman, J.G. Gaps in the childhood malaria burden in Africa: cerebral malaria, neurological sequelae, anemia, respiratory distress, hypoglycemia, and complications of pregnancy. Am. J. Trop. Med. Hyg., 2001, 64(Suppl 1-2), 57-67.

[72] Brabin, B.J.; Romagosa, C.; Abdelgalil, S.; Menéndez, C.; Verhoeff, F.H.; McGready, R.; Fletcher, K.A.; Owens, S.; D'Alessandro, U.; Nosten, F.; Fischer, P.R.; Ordi, J. The sick placenta-the role of malaria. Placenta, 2004, 25(5), 359-378.

[73] Suguitan, A.L. Jr; Leke, R.G.; Fouda, G.; Zhou, A.; Thuita, L.; Metenou, S.; Fogako, J.; Megnekou, R.; Taylor, D.W. Changes in the levels of chemokines and cytokines in the placentas of women with Plasmodium falciparum malaria. J. Infect. Dis., 2003, 188(7), 1074-1082.

[74] Duffy, P.E. Maternal immunization and malaria in pregnancy. Vaccine, 2003, 21(24), 3358-3361.

[75] Dorman, E.K; Shulman, C.E.; Kingdom, J.; Marsh, K. Impaired utero-placental blood flow in pregnancies complicated by falciparum malaria. J. Obstet. Gynecol., 2000, 20(1), 15-23.

[76] Rogerson, S.J.; Pollina, E.; Getachew, A.; Tadesse, E.; Lema, V.M.; Molyneux, M.E. Placental monocyte infiltrates in response to Plasmodium falciparum malaria infection and their association with adverse pregnancy outcomes. Am. J. Trop. Med. Hyg., 2003, 68(1), 115-119.

[77] Walter, P.R.; Garin, Y.; Blot, P. Placental pathologic changes in malaria. A histologic and ultrastructural study. Am. J. Pathol., 1982, 109(3), 330-342.

[78] Le Hesran, J.Y.; Cot, M.; Personne, P.; Fievet, N.; Dubois, B.; Beyemé, M.; Boudin, C.; Deloron, P. Maternal placental infection with Plasmodium falciparum and malaria morbidity during the first 2 years of life. Am. J. Epidemiol., 1997, 146(10), 826-831.

[79] Duffy, P.E.; Fried, M. Antibodies that inhibit Plasmodium falciparum adhesion to chondroitin sulfate A are associated with increased birth weight and the gestational age of newborns. Infect. Immun., 2003, $71(11), 6620-6623$.

[80] Staalsoe, T.; Shulman, C.E.; Bulmer, J.N.; Kawuondo, K.; Marsh, K.; Hviid, L. Variant surface antigen-specific IgG and protection against clinical consequences of pregnancy-associated Plasmodium falciparum malaria. Lancet, 2004, 363(9405), 283-289.

[81] Tuikue Ndam, N.G.; Salanti, A.; Le-Hesran, J.Y.; Cottrell, G.; Fievet, N.; Turner, L.; Sow, S.; Dangou, J.M.; Theander, T.; Deloron, P. Dynamics of anti-VAR2CSA immunoglobulin G response in a cohort of senegalese pregnant women. J. Infect. Dis., 2006, 193(5), 713-20.

[82] Ned, R.M.; Moore, J.M.; Chaisavaneeyakorn, S.; Udhayakumar, V. Modulation of immune responses during HIV-malaria co-infection in pregnancy. Trends Parasitol., 2005, 21(6), 284-291.

[83] Ferrante, P.; Delbue, S.; Mancuso, R. The manifestation of AIDS in Africa: an epidemiological overview. J. Neurovirol., 2005, 11 (Suppl 1), 50-57.

[84] Flateau, C.; Le Loup, G.; Pialoux, G. Consequences of HIV infection on malaria and therapeutic implications: a systematic review. Lancet Infect. Dis., 2011, 11(7), 541-556.

[85] Mount, A.M.; Mwapasa, V.; Elliott, S.R.; Beeson, J.G.; Tadesse, E.; Lema, V.M.; Molyneux, M.E.; Meshnick, S.R.; Rogerson, S.J. Impairment of humoral immunity to Plasmodium falciparum malaria in pregnancy by HIV infection. Lancet, 2004, 363(9424), 1860-1867.

[86] Tkachuk, A.N.; Moormann, A.M.; Poore, J.A.; Rochford, R.A.; Chensue, S.W.; Mwapasa, V.; Meshnick, S.R. Malaria enhances expression of CC chemokine receptor 5 on placental macrophages. J. Infect. Dis., 2001, 183(6), 967-972.

[87] Ayisi, J.G.; van Eijk, A.M.; Newman, R.D.; ter Kuile, F.O.; Shi, Y.P.; Yang, C.; Kolczak, M.S.; Otieno, J.A.; Misore, A.O.; Kager, P.A.; Lal, R.B.; Steketee, R.W.; Nahlen, B.L. Maternal malaria and perinatal HIV transmission, western Kenya. Emerg. Infect Dis., 2004, 10(4), 643-652.

[88] Ayisi, J.G.; van Eijk, A.M.; ter Kuile, F.O.; Kolczak, M.S.; Otieno, J.A.; Misore, A.O.; Kager, P.A.; Steketee, R.W.; Nahlen, B.L. The effect of dual infection with HIV and malaria on pregnancy outcome in western Kenya. AIDS, 2003, 17(4), 585-594.

[89] Okoko, B.J.; Wesumperuma, L.H.; Ota, M.O.; Pinder, M.; Banya, W.; Gomez, S.F.; McAdam, K.P.; Hart, A.C. The influence of placental malaria infection and maternal hypergammaglobulinemia on transplacental transfer of antibodies and $\mathrm{IgG}$ subclasses in a rural West African population. J. Infect. Dis., 2001, 184(5), 627-632.

[90] McGregor, I.A.; Barr, M. Antibody response to tetanus toxoid inoculation in malarious and non-malarious Gambian children. Trans. R. Soc. Trop. Med. Hyg., 1962, 56(9), 364-367.

[91] WHO. Malaria Control Among Refugees And Displaced Populations. World Health Organization: Geneva, 1996.

[92] Worrall, E.; Morel, C.; Yeung, S.; Borghi, J.; Webster, J.; Hill, J.; Wiseman, V.; Mills, A. The economics of malaria in pregnancy - a review of the evidence and research priorities. Lancet Infect. Dis., 2007, 7(2), 156-168.

[93] Bloland, P.B.; Kachur, S.P.; Williams, H.A. Trends in antimalarial drug deployment in sub-Saharan Africa. J. Exp. Biol., 2003, 206(21), 3761-3769.

[94] WHO. Pregnancy, Childbirth, Postpartum And Newborn Care: A Guide For Essential Practice. World Health Organization: Geneva, 2003.

[95] Greenwood, B.; Alonso, P.; ter Kuile, F.O.; Hill, J.; Steketee, R.W. Malaria in pregnancy: priorities for research. Lancet Infect. Dis., 2007, 7(2), 169-174.

[96] CIAM. Annual Report 2007. Available at: http://www.ciam.gm/_ library/2009/12/annual\%20 report\%202007.pdf (accessed August 3,2011 ).

[97] Smith, J.D.; Deitsch, K.W. Pregnancy-associated malaria and the prospects for syndrome-specific antimalaria vaccines. J. Exp. Med., 2004, 200(9), 1093-1097.

[98] Ayala FJ, Escalante AA, Rich SM. Evolution of Plasmodium and the recent origin of the world populations of Plasmodium falciparum. Parassitologia, 1999, 41(1-3), 55-68.

[99] Bockhorst, J.; Lu, F.; Janes, J.H.; Keebler, J.; Gamain, B.; Awadalla, P.; Su, X.Z.; Samudrala, R.; Jojic, N.; Smith, J.D. Structural polymorphism and diversifying selection on the pregnancy malaria vaccine candidate VAR2CSA. Mol. Biochem. Parasitol., 2007, 155(2), 103-112.

[100] Saul, A. The role of variant surface antigens on malaria-infected red blood cells. Parasitol. Today, 1999, 15(11), 455-457.

[101] Urban, B.C.; Ferguson, D.J.; Pain, A.; Willcox, N.; Plebanski, M.; Austyn, J.M.; Roberts, D.J. Plasmodium falciparum-infected erythrocytes modulate the maturation of dendritic cells. Nature, 1999, 400(6739), 73-77.

[102] Scherf, A.; Lopez-Rubio, J.J.; Riviere, L. Antigenic variation in Plasmodium falciparum. Annu. Rev. Microbiol., 2008, 62(1), 445470.

[103] Fried, M.; Wendler, J.P.; Mutabingwa, T.K.; Duffy, P.E. Mass spectrometric analysis of Plasmodium falciparum erythrocyte membrane protein-1 variants expressed by placental malaria parasites. Proteomics, 2004, 4(4), 1086-1093.

[104] Nielsen, M.A.; Resende, M.; Alifrangis, M.; Turner, L.; Hviid, L.; Theander, T.G.; Salanti, A. Plasmodium falciparum: VAR2CSA expressed during pregnancy-associated malaria is partially resistant to proteolytic cleavage by trypsin. Exp. Parasitol., 2007, 117(1), $1-8$.

[105] Hviid, L. Development of vaccines against Plasmodium falciparum malaria: taking lessons from naturally acquired protective immunity. Microbes Infect., 2007, 9(6), 772-776.

[106] Achur, R.N.; Valiyaveettil, M.; Gowda, D.C. The low sulfated chondroitin sulfate proteoglycans of human placenta have sulfate group-clustered domains that can efficiently bind Plasmodium falciparum-infected erythrocytes. J. Biol. Chem., 2003, 278(13), 11705-11713.

[107] Pouvelle, B.; Meyer, P.; Robert, C.; Bardel, L.; Gysin, J. Chondroitin-4-sulfate impairs in vitro and in vivo cytoadherence of Plasmodium falciparum infected erythrocytes. Mol. Med., 1997, 3(8), 508-518.

[108] Conte, A.; de Bernardi, M.; Palmieri, L.; Lualdi, P.; Mautone, G.; Ronca, G. Metabolic fate of exogenous chondroitin sulfate in man. Arzneimittelforschung, 1991, 41(7), 768-772.

[109] Duffy, P.E.; Krzych, U.; Francis, S.; Fried, M. Malaria vaccines: using models of immunity and functional genomics tools to accelerate the development of vaccines against Plasmodium falciparum. Vaccine, 2005, 23(17-18), 2235-2242.

[110] Singh, S.K.; Hora, R.; Belrhali, H.; Chitnis, C.E.; Sharma, A. Structural basis for Duffy recognition by the malaria parasite Duffy-binding-like domain. Nature, 2006, 439(7077), 741-744. 
[111] Costa, F.T.; Fusaï, T.; Parzy, D.; Sterkers, Y.; Torrentino, M.; Douki, J.B.; Traoré, B.; Petres, S.; Scherf, A.; Gysin, J. Immunization with recombinant duffy binding-like-gamma3 induces pan-reactive and adhesion-blocking antibodies against placental chondroitin sulfate A-binding Plasmodium falciparum parasites. J. Infect. Dis., 2003, 188(1), 153-164.

[112] Brannan, L.R.; Turner, C.M.; Phillips, R.S. Malaria parasites undergo antigenic variation at high rates in vivo. Proc. Biol. Sci., 1994, 256(1345), 71-75.

[113] Scherf, A. A greedy promoter controls malarial var-iations. Cell, 2006, 124(2), 251-253.

[114] Freitas-Junior, L.H.; Hernandez-Rivas, R.; Ralph, S.A.; MontielCondado, D.; Ruvalcaba-Salazar, O.K.; Rojas-Meza, A.P.; MâncioSilva, L.; Leal-Silvestre, R.J.; Gontijo, A.M.; Shorte, S.; Scherf, A. Telomeric heterochromatin propagation and histone acetylation control mutually exclusive expression of antigenic variation genes in malaria parasites. Cell, 2005, 121(1), 25-36.

[115] Voss, T.S.; Healer, J.; Marty, A.J.; Duffy, M.F.; Thompson, J.K.; Beeson, J.G.; Reeder, J.C.; Crabb, B.S.; Cowman, A.F. A var gene promoter controls allelic exclusion of virulence genes in Plasmodium falciparum malaria. Nature, 2006, 439(7079), 10041008.

[116] Lekana Douki, J.B.; Traore, B.; Costa, F.T.; Fusaï, T.; Pouvelle, B.; Sterkers, Y.; Scherf, A.; Gysin, J. Sequestration of Plasmodium falciparum-infected erythrocytes to chondroitin sulfate A, a receptor for maternal malaria: monoclonal antibodies against the native parasite ligand reveal pan-reactive epitopes in placental isolates. Blood, 2002, 100(4), 1478-1483.

[117] Bir, N.; Yazdani, S.S.; Avril, M.; Layez, C.; Gysin, J.; Chitnis, C.E. Immunogenicity of Duffy binding-like domains that bind chondroitin sulfate $\mathrm{A}$ and protection against pregnancy-associated malaria. Infect. Immun., 2006, 74(10), 5955-5963.

[118] Hviid, L. The role of Plasmodium falciparum variant surface antigens in protective immunity and vaccine development. Hum. Vaccin., 2010, 6(1), 84-89.

[119] Salanti, A.; Dahlbäck, M.; Turner, L.; Nielsen, M.A.; Barfod, L.; Magistrado, P.; Jensen, A.T.; Lavstsen, T.; Ofori, M.F.; Marsh, K.;
Hviid, L.; Theander, T.G. Evidence for the involvement of VAR2CSA in pregnancy-associated malaria. J. Exp. Med., 2004, 200(9), 1197-1203.

[120] Todryk, S.M.; Walther, M. Building better T-cell-inducing malaria vaccines. Immunology, 2005, 115(2), 163-169.

[121] Li, S.; Locke, E.; Bruder, J.; Clarke, D.; Doolan, D.L.; Havenga, M.J.; Hill, A.V.S.; Liljestrom, P.; Monath, T.P.; Naim, H.Y.; Ockenhouse, C.; Tang, D.C.; Van Kampen, K.R.; Viret, J.F.; Zavala, F.; Dubovsky, F. Viral vectors for malaria vaccine development. Vaccine, 2007, 25(14), 2567-2574.

[122] Liu, M.A. DNA vaccines: a review. J. Intern. Med., 2003, 253(4), 402-410.

[123] Hill, A.V.S.; Reyes-Sandoval, A.; O'Hara, G.; Ewer, K.; Lawrie, A.; Goodman, A.; Nicosia, A.; Folgori, A.; Colloca, S.; Cortese, R.; Gilbert, S.C.; Draper, S.J. Prime-boost vectored malaria vaccines: progress and prospects. Hum. Vaccin., 2010, 6(1), 78-83.

[124] Menendez, C.; Alonso, P. Guidelines and considerations for testing malaria vaccines in pregnant women. Hum. Vaccin., 2010 , 6(1), 21-26.

[125] Plebanski, M.; Gilbert, S.C.; Schneider, J.; Hannan, C.M.; Layton, G.; Blanchard, T.; Becker, M.; Smith, G.; Butcher, G.; Sinden, R.E.; Hill, A.V.S. Protection from Plasmodium berghei infection by priming and boosting $\mathrm{T}$ cells to a single class I-restricted epitope with recombinant carriers suitable for human use. Eur. J. Immunol., 1998, 28(12), 4345-4355.

[126] Craig, A.G. Pregnancy-associated malaria - on the brink? Trends Parasitol., 2004, 20(5), 201-204

[127] Crompton, P.D.; Pierce, S.K.; Miller, L.H. Advances and challenges in malaria vaccine development. J. Clin. Invest., 2010 120(12), 4168-4178.

[128] Casares, S.; Brumeanu, T.D.; Richie, T.L. The RTS,S malaria vaccine. Vaccine, 2010, 28(31), 4880-4894.

[129] The RTS,S Clinical Trials Partnership. First results of phase 3 trial of RTS,S/AS01 malaria vaccine in African children. N. Engl. J. Med., 2011, 365(9), 1863-1875.

[130] Butler, D. Malaria vaccine results face scrutiny. Nature, 2011, 478(7370), 439-440

(C) Morley and Taylor-Robinson; Licensee Bentham Open.

This is an open access article licensed under the terms of the Creative Commons Attribution Non-Commercial License (http://creativecommons.org/licenses/bync/3.0/) which permits unrestricted, non-commercial use, distribution and reproduction in any medium, provided the work is properly cited. 